\title{
Thermal Stability of ZIF-8 Membranes for Gas Separations
}

\author{
Joshua B. James and Y. S. Lin* \\ Chemical Engineering, School for Engineering of Matter, Transport and Energy \\ Arizona State University \\ Tempe, AZ 85287 \\ *Corresponding Author; Email \& Phone Number: jerry.lin@ asu.edu, 480-965-7769
}




\begin{abstract}
The thermal stability of ZIF membranes is important for high temperature separation applications but has not been systematically studied. This work highlights the results of a thermal stability study of ZIF-8 membranes in terms of material structure, $\mathrm{H}_{2} / \mathrm{CO}_{2}$ gas permeation and separation characteristics. During binary and single gas temperature dependent permeance tests conducted from $25-250^{\circ} \mathrm{C}$, both $\mathrm{H}_{2}$ and $\mathrm{CO}_{2}$ permeances decrease as a function of temperature. In the binary test, $\mathrm{H}_{2} / \mathrm{CO}_{2}$ selectivity increases between $25-225^{\circ} \mathrm{C}$, and then decreases as temperature is further increased between $225-275^{\circ} \mathrm{C}$. The results can be explained by the adsorption/diffusion mechanism. Beyond $275^{\circ} \mathrm{C}, \mathrm{H}_{2} / \mathrm{CO}_{2}$ permeance and selectivity drastically increase with respect to temperature and is indicative of ZIF-8 membrane partial carbonization during the dynamic 30 hour temperature dependent test. The time/temperature dependency of the onset of ZIF-8 thin film structural change was deconvoluted in isothermal transient permeation experiments. Transient tests performed at $50,100,150$ and $300^{\circ} \mathrm{C}$ for 24 hours indicate that ZIF8 thin films maintain their crystallinity and structural integrity below $150^{\circ} \mathrm{C}$. However, at temperatures of $150^{\circ} \mathrm{C}$ and greater the framework undergoes increased magnitudes of thermally induced carbonization as a function of temperature. Thermomechanically induced stresses between the ZIF-8 membrane thin film and $\alpha$-alumina support may account for differences in static thermal stability observed when comparing ZIF-8 membranes and ZIF-8 crystalline powders.
\end{abstract}

\title{
Keywords:
}

ZIF-8 membrane, Thermal stability, High temperature, Membrane carbonization, Gas separation

* Corresponding Author: Jerry.Lin@asu.edu 


\section{Introduction}

Recent research has placed a large focus on the newest subset of metal-organic frameworks termed ZIFs or zeolitic imidazolate frameworks. ZIFs have been highlighted as highly ordered nanoporous materials possessing zeolitic topologies [1]. Two highly cited advantages of ZIFs over their zeolite, polymer and silica counterparts are the ability to precisely tune ZIFs for a specific kinetic or thermodynamic separation and exceptionally large surface areas [2]. These properties are achieved through the ability to select from a vast number of imidazole linkers of various functionalities and metal node $(\mathrm{Co}, \mathrm{Cd}, \mathrm{Cu}, \mathrm{Zn})$ interchangeability $[3,4]$. In addition to structural adaptability, ZIFs have been cited as possessing exceptional chemical and thermal stability which is attributable to hydrophobic pores and strong metalimidazole bonds [1].

Due to its ease of synthesis with benign precursors, large pore size $(1.16 \mathrm{~nm})$ for sizeable gas uptake/permeability and small pore aperture $(0.34 \mathrm{~nm})$ for molecular sieving, ZIF-8 is the most prevalent ZIF studied and accounts for over $70 \%$ of zeolitic imidazolate framework literature citations [5]. The intrinsic structural properties of ZIF-8 make it an ideal candidate as a hydrogen selective membrane [6,7]. Hydrogen selective membranes have potential application in water-gas shift and hydrocarbon dehydrogenation membrane reactor/membrane-assisted reactor applications which typically operate at temperatures of $180^{\circ} \mathrm{C}$ or greater $[8,9]$. A fundamental understanding of the thermal limitations of ZIF-8 membrane thin films is of great importance for valuation of future ZIF-8 applications.

The thermal stability of ZIF-8 membrane precursor crystals in powder form has been previously studied, and dynamic thermal gravimetric analyses (TGA) report thermal decomposition onset temperatures between $400-550^{\circ} \mathrm{C}[10,11]$. The span of ZIF-8 crystal 
decomposition temperatures is dependent upon decomposition environment (inert vs oxidizing), crystal size and TGA conditions [12,13]. More industrially relevant isothermal studies of ZIF-8 crystal thermal stability have been performed and consensus between studies seem to substantiate that ZIF-8 nanocrystals are kinetically stable up to approximately $200^{\circ} \mathrm{C}$ in inert, oxidizing and reducing atmospheres $[11,14,15]$. Our previous study on ZIF-8 thermal stability revealed a slight elimination of ZIF-8 crystallinity when subjecting crystals to isothermal temperatures of $250^{\circ} \mathrm{C}$ or greater for 20 hours in each environment [15]. When held at $300^{\circ} \mathrm{C}$ for 20 hours, ZIF-8 crystals underwent partial carbonization in inert, oxidizing and reducing atmospheres to form an imidazole-Zn-azirine structure as postulated though evidence obtained from multiple characterization techniques [15].

ZIF enabled membranes including ZIF-7, ZIF-8/PBI and ZIF-90 have each displayed promising thermal stability with stable hydrogen separation at temperatures of $200^{\circ} \mathrm{C}$ and greater [16-18]. Specific to ZIF-8 enabled membranes, Caro and co-workers prepared ZIF-8 membranes using novel polydopamine functionalized supports and reported $\mathrm{H}_{2} / \mathrm{CO}_{2}$ separation factors of 8.1 and 8.9 respectively at temperatures of 100 and $150^{\circ} \mathrm{C}$ respectively $[19,20]$, however the single data points collected at each temperature do not give indication of thermal stability.

Zhang et al. performed successive single gas permeation experiments with $\mathrm{ZnO}$ nanorod supported ZIF-8 membranes from $25-200^{\circ} \mathrm{C}$ in $\mathrm{H}_{2}, \mathrm{CO}_{2}, \mathrm{~N}_{2}$ and $\mathrm{CH}_{4}$ atmospheres and noted that the membrane remained defect free after repeated heating and cooling for each single gas test [21]. Drobek and co-workers formed ZIF-8 membranes through a novel $\mathrm{ZnO}$ atomic layer deposition (ALD) conversion method and performed binary $\mathrm{H}_{2} / \mathrm{CO}_{2}$ separation from $25-100^{\circ} \mathrm{C}$ and observed an increasing separation factor from $\sim 3.2-7.8$ with respect to temperature [22]. The studies by Zhang and Drobek stressed the use of $\mathrm{ZnO}$ interlayers between the ZIF-8 thin film and 
$\alpha$-alumina supports to compensate for the thermal expansion coefficient mismatch between $\alpha$ alumina and ZIF-8 to decrease the likelihood of thin film cracking upon successive heating and cooling between experiments.

The aforementioned works provided insight to solving a specific dynamic, thermomechanical stability issue for ZIF-8 membranes, however there has yet to be a static or isothermal stability study which simultaneously observes changes in the physical characteristics and separation performance of ZIF-8 membrane thin films as a result of sustained thermal stress. The present work and experiments within are designed to obtain a fundamental understanding of thermal stability of the ZIF-8 membrane for gas permeation and separation using $\mathrm{H}_{2}$ and $\mathrm{CO}_{2}$ as a sample gas mixture.

\section{Experimental}

\subsection{ZIF-8 Membrane Synthesis and Characterization}

ZIF-8 membranes were prepared according to our previously reported method with a few modifications [23]. $\alpha$-alumina membrane supports $22 \mathrm{~mm}$ in diameter and $2 \mathrm{~mm}$ thick (average pore diameter: $120 \mathrm{~nm}$, porosity: 45\% were custom prepared using A-16 calcinated alumina powder (Almantis). After sintering at $1150^{\circ} \mathrm{C}$ for 30 hours, $\alpha$-alumina disks were polished to form a smooth membrane substrate using 500, 800, 1200, and 2000 silicon carbide (SiC)

polishing paper (Struers). The supports were then washed under sonication for 10 minutes in 20 $\mathrm{mL}$ of pure deionized water, then for 10 minutes in pure methanol for removal of impurities. After 5 minutes in each solvent, full liquid exchange was performed to provide a fresh bath. The supports were subsequently dried at $250^{\circ} \mathrm{C}$ for 4 hours after washing. 
ZIF-8 crystals were prepared by the method reported by Cravillion et al. [24]. $734.4 \mathrm{mg}$ of zinc nitrate hexahydrate $\left[\mathrm{Zn}\left(\mathrm{NO}_{3}\right)_{2} \bullet 6 \mathrm{H}_{2} \mathrm{O}\right](99.0 \%$ Alpha Aesar) and $810.6 \mathrm{mg}$ of 2methylimidazole (99\% Sigma Aldrich) were each dissolved separately in $250 \mathrm{~mL}$ beakers containing $25 \mathrm{~mL}$ of methanol and stirred for 30 minutes. The 2-methylimidazole solution was then added slowly to the zinc nitrate solution under stirring and mixed for 6 hours. After amalgamation, the mixture was aged for 24 hours without stirring. White precipitate crystals were collected after 3 cycles of centrifugation and washing with methanol (99\% BDH). After washing, the ZIF-8 seeds were placed under vacuum (60 kPa) for 12 hours at room temperature. A stable, well dispersed colloidal solution of ZIF-8 nuclei was prepared by forming a $0.035 \mathrm{wt} \%$ ZIF-8 suspension in methanol.

An earlier prepared $\alpha$-alumina disk support with polished side down was brought in contact with the ZIF-8 seed solution for 10 seconds followed by drying in air for 10 minutes, the preceding steps were then conducted a second time. Two dip-coatings were performed for short time intervals to decrease the probability of forming seed layer cracks while ensuring homogenous seed coverage across the entire substrate. The ZIF-8 seed coated disk was placed in an oven and ramped by $0.3^{\circ} \mathrm{C} / \mathrm{min}$ to $95^{\circ} \mathrm{C}$, held for 3 hours then ramped down to room temperature at the same rate.

A seeded secondary growth method adapted from Pan et al. [25] was utilized to promote growth of a thin, continuous, defect-free membrane layer across the $\alpha$-alumina substrate. The secondary growth solution was prepared by dissolving $2.27 \mathrm{~g}$ of 2-methylimidazole and $0.12 \mathrm{~g}$ of $\mathrm{Zn}\left(\mathrm{NO}_{3}\right)_{2} \bullet 6 \mathrm{H}_{2} \mathrm{O}$ in $40 \mathrm{~mL}$ of deionized water. The seeded disk was placed vertically with the polished face tilted slightly up in a Teflon holder contained within a $45 \mathrm{~mL}$ Teflon lined stainless steel autoclave. The clear secondary growth solution was poured slowly into the Teflon container 
and immersed the seeded support. Secondary growth was carried out at $130^{\circ} \mathrm{C}$ for 6.5 hours. After membrane growth the stainless steel autoclave was removed from the oven and cooled to room temperature. The ZIF-8 membrane was removed from the secondary growth solution, washed briefly with deionized water then immersed in a methanol bath for 6.5 hours to exchange solvent within the membrane pores. After solvent exchange the membrane was placed under vacuum $(60 \mathrm{kPa})$ for 12 hours at room temperature. The secondary growth synthesis was repeated again to seal defects and generate a highly crystalline ZIF-8 structure in a highly reproducible process.

Membrane surface morphology and cross section analyses were conducted using an XL30 Environmental FEG (FEI) scanning electron microscope (SEM) with an accelerating voltage of $20 \mathrm{kV}$. Samples underwent gold/palladium deposition prior to imaging to prevent surface charging. The ZIF-8 membrane crystal structure was examined using a Bruker D8 x-ray diffractometer at $20 \mathrm{kV}, 5 \mathrm{~mA}$ with a scan speed of $2 \%$ min about $2 \theta$ using $\mathrm{Cu} \mathrm{K} \alpha$ radiation $(\lambda=$ $0.1543 \mathrm{~nm})$. ZIF-8 membrane functional group characterization was observed using a Thermo Nicolet 6700 Fourier transform infrared spectrometer equipped with a deuterated triglycine sulfate (DTGS) detector element and a diamond window. An $\alpha$-alumina support was used as a zero background so that only ZIF-8 spectral peaks were displayed.

\subsection{Gas Permeation/Separation Experiments and Thermal Gravimetric Analysis}

Each as-synthesized $\alpha$-alumina supported ZIF-8 membrane was sealed into a stainless steel permeation cell using VITON O-rings (O-rings West). The permeation area of each membrane was $2.27 \times 10^{-4} \mathrm{~m}^{2}$. All membranes were probed at room temperature using helium (He) and sulfur hexafluoride $\left(\mathrm{SF}_{6}\right)$ to evaluate their molecular sieving transport characteristics 
using a single gas steady-state permeation system [23]. He or $\mathrm{SF}_{6}$ was supplied to the permeation cell directly from tubing attached to each respective gas cylinder and maintained at 20 psig using a needle valve. The permeate side was connected to a bubble flow meter at atmospheric pressure without a sweep gas.

Membrane permeance $F_{i}$ of component $i$ is defined as:

$F_{i}=\frac{Q_{i}}{\Delta P_{i} A}$

where $Q_{i}$ is the permeate molar flow rate of component $\mathrm{i}(\mathrm{mol} / \mathrm{s}), \Delta P_{i}$ the transmembrane pressure drop of $\mathrm{i}(\mathrm{Pa})$ and $\mathrm{A}$, is the effective permeation area $\left(\mathrm{m}^{2}\right)$. Ideal or permselectivity in molecular probing experiments is defined by the ratio of pure gas permeances:

Ideal Selectivity $=\frac{F_{i}}{F_{j}}$

where $\mathrm{j}$ denotes larger kinetic diameter component $\mathrm{j}$.

Hydrogen/carbon dioxide single gas, binary temperature dependent and binary transient permeance experiments were performed using the Wicke-Kallenbach technique shown in Figure 1. For the single, binary temperature dependent and binary transient gas permeance experiments, $\mathrm{H}_{2}$ and $\mathrm{CO}_{2}$ feed gases were each maintained at $25 \mathrm{~mL} / \mathrm{min}$ (50:50 mol ratio) and nitrogen sweep gas at $50 \mathrm{~mL} / \mathrm{min}$ using mass flow controllers. Volumetric flow rates correspond to ambient temperatures ranging between $23.6-25.0^{\circ} \mathrm{C}$ and a pressure of 1 atmosphere. In each experiment, 
both the feed and sweep sides of the permeation cell were maintained at 1 atmosphere. The feed pressure was controlled by a needle valve on the retentate side (fully open) and the sweep side pressure was maintained using $\mathrm{N}_{2}$ sweep gas. The composition of both the retentate and sweep gasses were analyzed by gas chromatography (GC) (Aligent $6890 \mathrm{~N}$, Alltech Haysep DB 100/120 column with dimensions: $9.1 \mathrm{~m}$ x $3.2 \mathrm{~mm}$ O.D. x $2.2 \mathrm{~mm}$ I.D., argon carrier gas and TCD detector). The single gas and binary temperature dependent permeance tests present $\mathrm{H}_{2} / \mathrm{CO}_{2}$ permeance behavior as a function of temperature. Temperatures were ramped by $1^{\circ} \mathrm{C} / \mathrm{min}$ from $25^{\circ} \mathrm{C}$ to $300^{\circ} \mathrm{C}\left(25-250^{\circ} \mathrm{C}\right.$ in single gas tests $)$ and held for 1.5 hours at each successive $25^{\circ} \mathrm{C}$ increment to reach a steady state permeance before collecting permeate and retentate compositions. Permeate and retentate composition collection by GC lasted approximately 30 minutes in total, then the furnace was ramped to the next $25^{\circ} \mathrm{C}$ temperature interval. In the transient tests, $\mathrm{H}_{2} / \mathrm{CO}_{2}$ mixture permeance was studied as a function of time over a 24 hour period at $50,100,150$ and $300^{\circ} \mathrm{C}$ respectively. A temperature ramping rate of $20^{\circ} \mathrm{C} / \mathrm{min}$ was used to isolate temperature and time effects on the ZIF-8 membrane structure and transport properties during the $300^{\circ} \mathrm{C}$ test. A ramping rate of $1{ }^{\circ} \mathrm{C} / \mathrm{min}$ was utilized in subsequent transient tests.

The mixture gas separation factor (SF) calculated in both the temperature dependent and time dependent experiments is defined by:

$\mathrm{SF}=\frac{y_{\mathrm{H}_{2}} / y_{\mathrm{CO}_{2}}}{x_{\mathrm{H}_{2}} / x_{\mathrm{CO}_{2}}}$

where y denotes permeate partial molar fraction and $\mathrm{x}$ denotes retentate partial molar fraction. Mixture permeance was calculated using the difference in retentate and permeate partial 
pressures as the driving force. Hydrogen permeance for example was calculated as follows during mixture gas tests

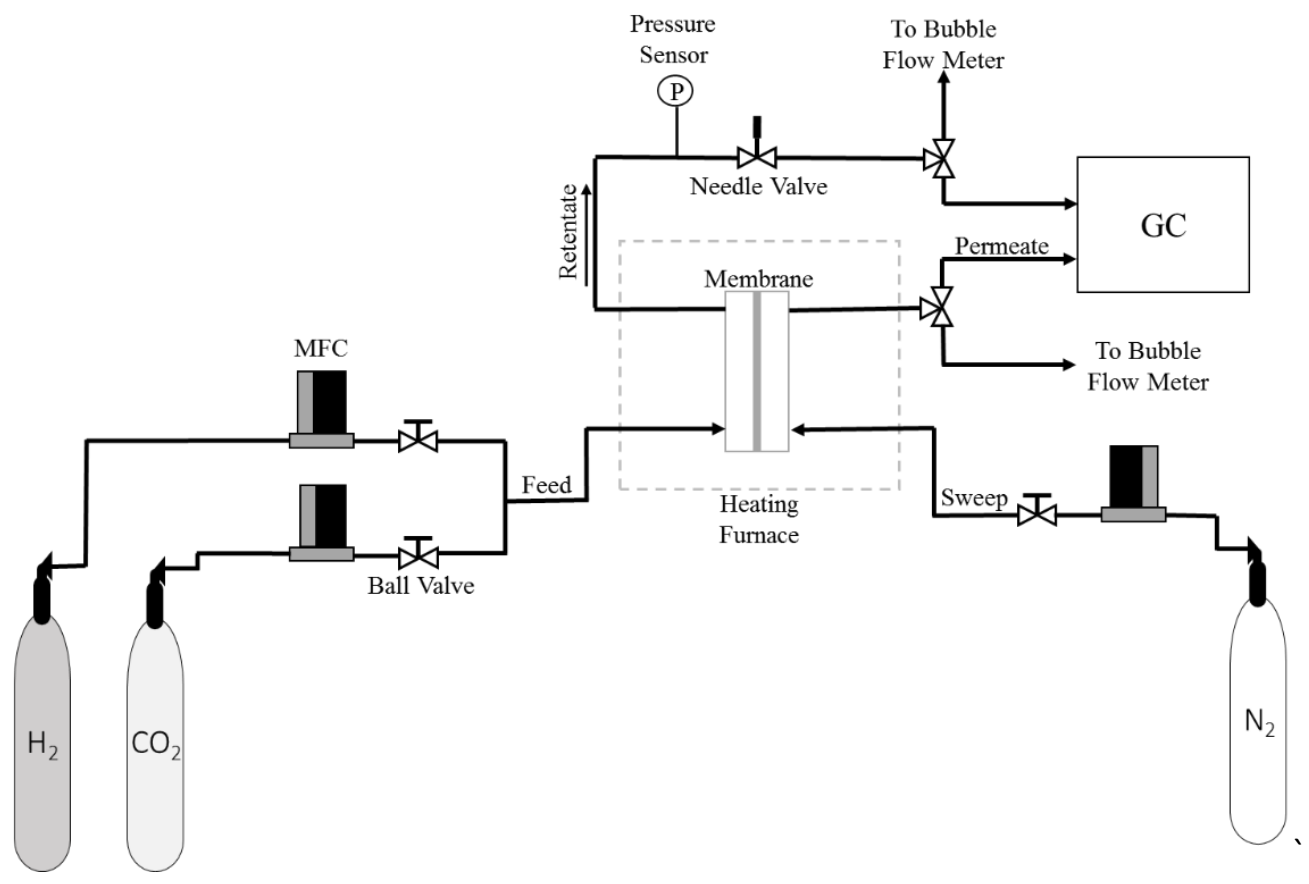

Figure 1. Binary gas permeance apparatus and configuration

$F_{H_{2}}=\frac{Q_{H_{2}}}{\left(x_{H_{2} P-y_{H_{2}} P}\right) * A}$

Carbon dioxide mixture permeance was calculated using the same method.

Thermal gravimetric analysis (TGA) measurements using ZIF-8 powders were utilized to help describe/prognosticate the underlying decomposition phenomena occurring during the ZIF8 binary temperature dependent membrane test. TGA analyses were conducted under $\mathrm{H}_{2} / \mathrm{CO}_{2}$ atmosphere using mass flow controllers to achieve a $25 \mathrm{~mL} / \mathrm{min}$ flow rate $(50: 50 \mathrm{~mol})$ in each respective gas at 1 atmosphere. The TGA test utilized a time and temperature profile identical to 
the binary mixture temperature dependent membrane experiment (ramp rate $1{ }^{\circ} \mathrm{C} / \mathrm{min}$, hold time 2 hours at each $25^{\circ} \mathrm{C}$ interval from $25-300^{\circ} \mathrm{C}$ ). The hold time of 2 hours corresponds to 1.5 hours to reach steady state followed by 30 minutes of GC sampling that occurred during membrane testing.

\section{Results and Discussion}

\subsection{Membrane Characteristics and Temperature Dependent Binary Separation Properties}

Figures 2 and 3 show cross-sectional, top surface view and XRD patterns representative of the as-synthesized ZIF-8 membranes obtained using the above synthesis procedure. SEM micrographs and sharp XRD pattern intensities at the corresponding $2 \theta$ values cohesively indicate the formation of $2.5-3.0 \mu \mathrm{m}$ thick, highly crystalline, continuous ZIF-8 films formed after membrane fabrication. Prior to $\mathrm{H}_{2} / \mathrm{CO}_{2}$ permeation tests, membranes underwent molecular probing with $\mathrm{He} / \mathrm{SF}_{6}$ to verify the presence of high integrity, molecular sieving ZIF-8 thin films present on the $\alpha$-alumina surface. The presence of large defects can significantly affect permeance behavior and molecular sieving properties.
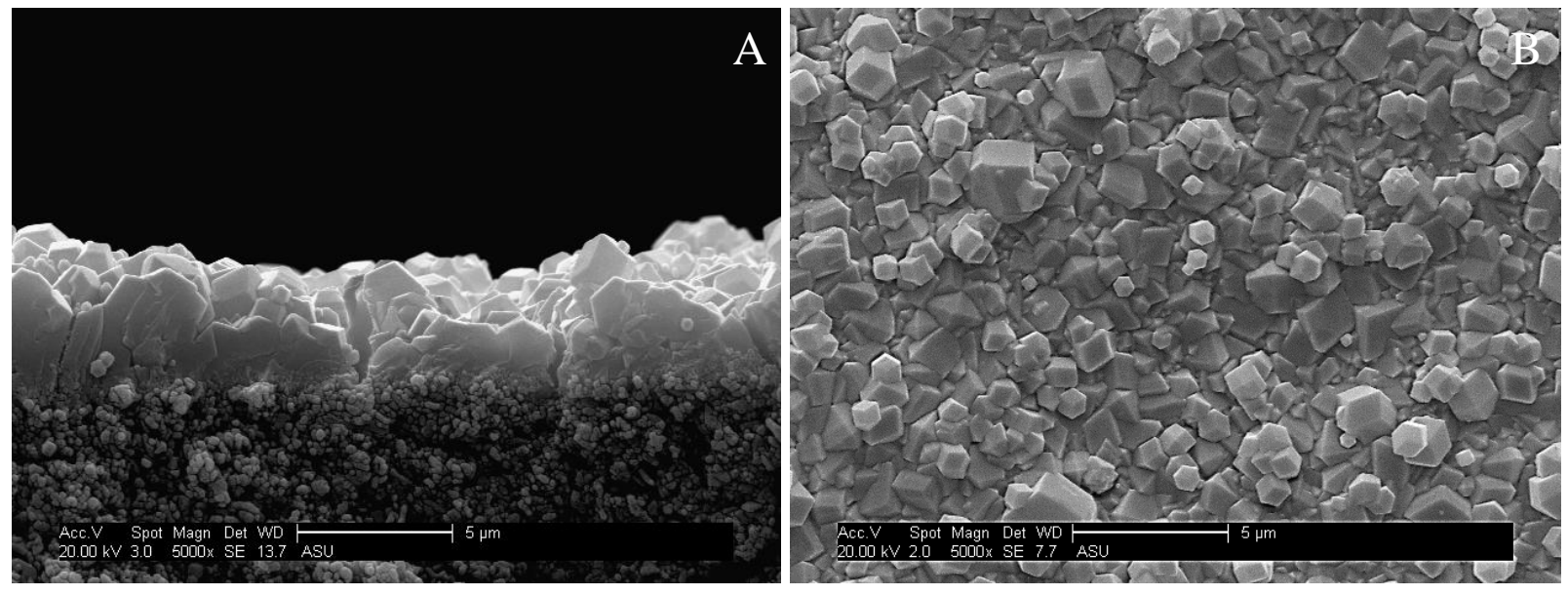

Figure 2. SEM micrograph of as-synthesized ZIF-8 membrane: cross section (A) and top view at 5000x magnification (B) 


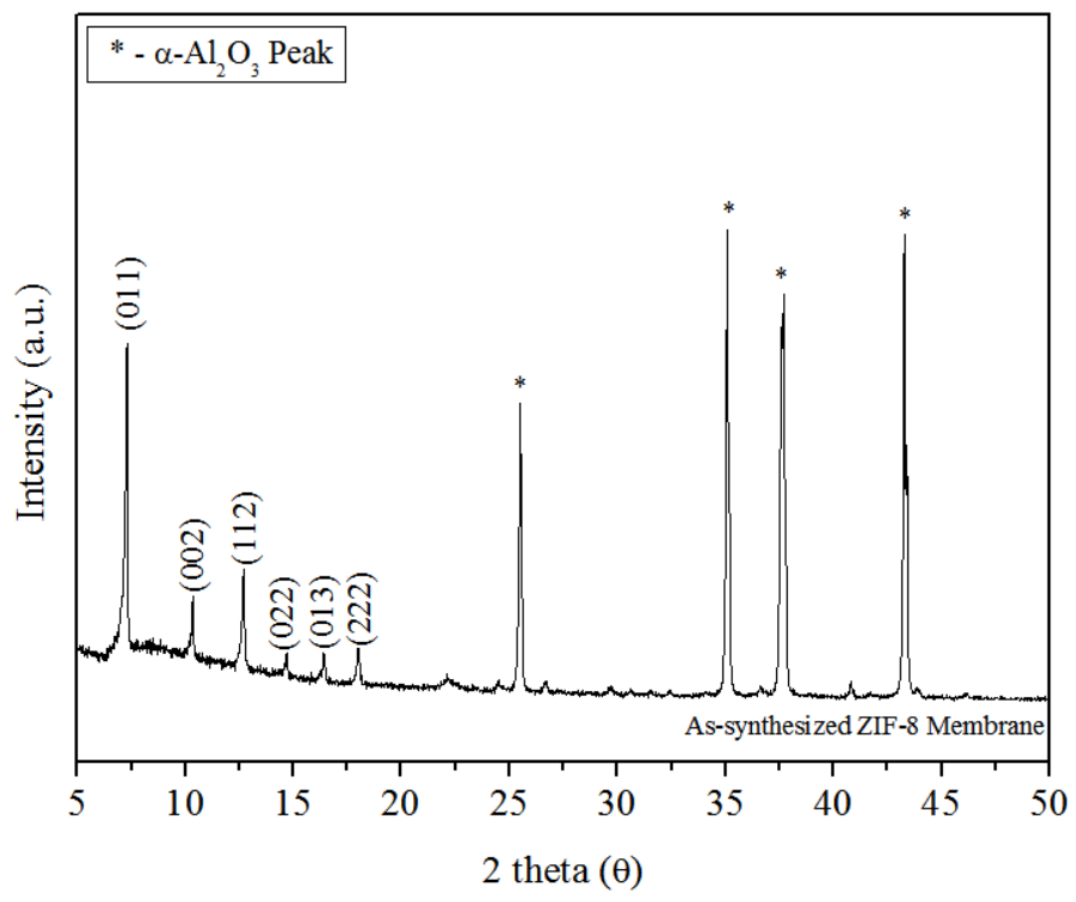

Figure 3. XRD pattern of as-synthesized ZIF-8 membrane on alumina support

Table 1 presents the single gas permeance and ideal separation factors for the membranes used in each permeation experiment. All membranes exhibit separation factors at least 60 times greater than the ideal Knudsen $\mathrm{He}_{\mathrm{SSF}}$ separation factor of 6.0 , which verifies synthesis of molecular sieving membranes.

Table 1. Permeance $\left(\mathrm{mol} / \mathrm{m}^{2} \mathrm{sPa}\right)$ and ideal $\mathrm{He}_{\mathrm{SF}} \mathrm{SF}_{6}$ Separation Factor Values for Membranes used in Thermal Stability Studies

\begin{tabular}{|c|c|c|c|c|}
\hline Membrane & He Permeance & $\mathrm{SF}_{6}$ Permeance & Ideal SF & Test Conducted \\
\hline M1 & $4.6 \times 10^{-7}$ & $1.1 \times 10^{-9}$ & 402 & $\mathrm{H}_{2}$ Single Gas \\
\hline M2 & $6.7 \times 10^{-7}$ & $1.7 \times 10^{-9}$ & 390 & $\mathrm{CO}_{2}$ Single Gas \\
\hline M3 & $9.1 \times 10^{-7}$ & $2.3 \times 10^{-9}$ & 395 & ${\mathrm{Binary} \mathrm{H}_{2} / \mathrm{CO}_{2}}^{-10}$ \\
\hline M4 & $6.5 \times 10^{-7}$ & $8.4 \times 10^{-10}$ & 775 & Transient $\mathrm{H}_{2} / \mathrm{CO}_{2}$ at $300^{\circ} \mathrm{C}$ \\
\hline M5 & $4.4 \times 10^{-7}$ & $1.1 \times 10^{-9}$ & 405 & Transient $\mathrm{H}_{2} / \mathrm{CO}_{2}$ at $150^{\circ} \mathrm{C}$ \\
\hline M6 & $4.4 \times 10^{-7}$ & $1.1 \times 10^{-9}$ & 395 & Transient $\mathrm{H}_{2} / \mathrm{CO}_{2}$ at $100^{\circ} \mathrm{C}$ \\
\hline M7 & $2.7 \times 10^{-7}$ & $5.1 \times 10^{-10}$ & 541 & Transient $\mathrm{H}_{2} / \mathrm{CO}_{2}$ at $50^{\circ} \mathrm{C}$ \\
\hline
\end{tabular}


Figure 4 shows $\mathrm{CO}_{2}$ and $\mathrm{H}_{2}$ single gas permeances as a function of temperature. The permeance of both $\mathrm{H}_{2}$ and $\mathrm{CO}_{2}$ decrease with respect to increasing temperature. Since diffusivity and solubility are directly and inversely proportional to temperature respectively, the results suggest that the activation energy for diffusion is smaller than heat of adsorption in ZIF-8 for both $\mathrm{H}_{2}$ and $\mathrm{CO}_{2}$. Molecular simulations incorporating specific force-field parameters to account for ZIF-8 framework flexibility indicate that the free energy of $\mathrm{CO}_{2}$ migration through the ZIF-8 crystalline network $(9.9 \mathrm{~kJ} / \mathrm{mol})$ is lower than the isoteric heat of adsorption $(14.19$ $\mathrm{kJ} / \mathrm{mol}$ ) [26]. The $\mathrm{CO}_{2}$ adsorptive affinity for the ZIF-8 framework is enabled by strong quadrupole- $\pi$ electrostatic interactions between the $\pi$ electrons of the imidazole ring and the partial positive charge of the carbon on $\mathrm{CO}_{2}[27,28]$. In addition to electrostatic affinity for $\mathrm{CO}_{2}$, the large cage diameter $(1.16 \mathrm{~nm})$ of the ZIF-8 structure enables significant equilibrium uptake of carbon dioxide (kinetic diameter $=0.33 \mathrm{~nm}$ ) [29].

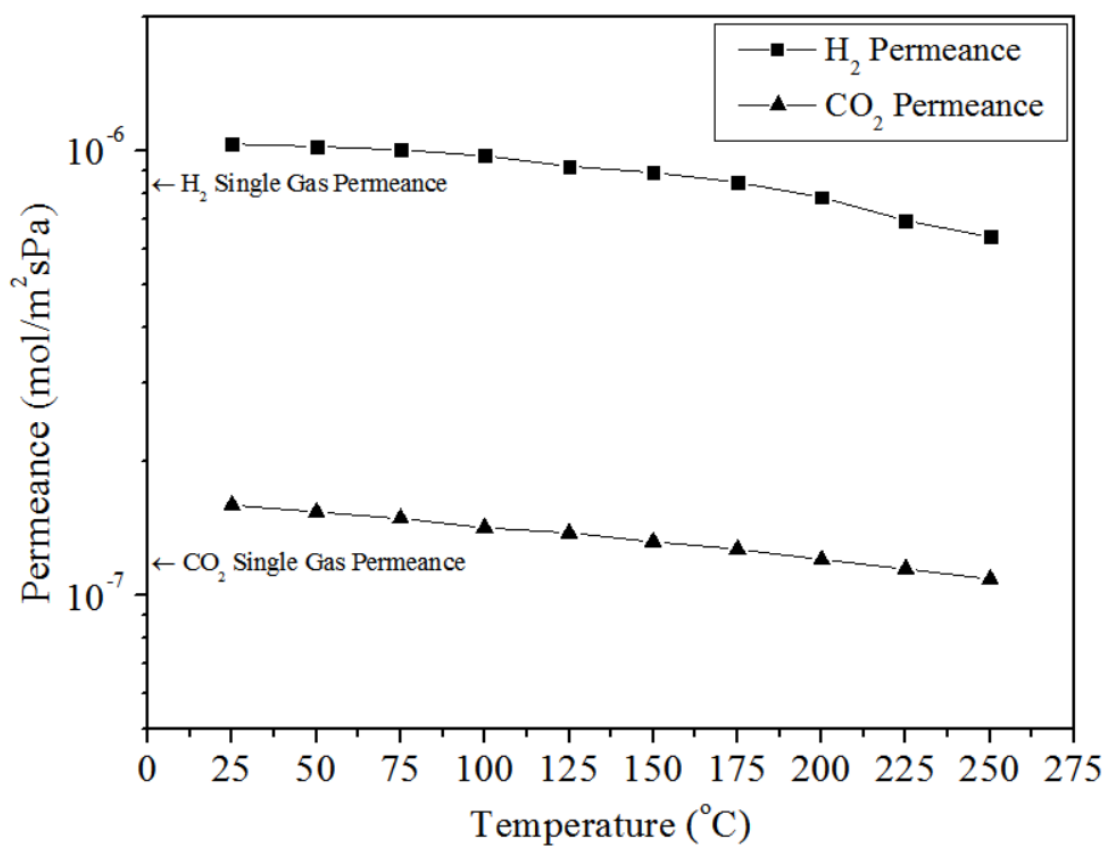

Figure 4. ZIF-8 membrane $\mathrm{H}_{2}$ and $\mathrm{CO}_{2}$ single gas permeance as a function of temperature from $25-250^{\circ} \mathrm{C}$ 
The temperature dependent $\mathrm{H}_{2}$ permeance plot in Figure 4 indicates a 38.2\% decrease in $\mathrm{H}_{2}$ permeance over the $25-250^{\circ} \mathrm{C}$ temperature range. This trend was also observed by Zhang et al. [20] who conducted hydrogen permeance as a function of temperature from $30^{\circ} \mathrm{C}$ to $200^{\circ} \mathrm{C}$ and observed a $65 \%$ decrease in hydrogen permeance $\left(15.9-5.6 \times 10^{-8} \mathrm{~mol} / \mathrm{m}^{2} \mathrm{sPa}\right)$ with incresing temperature. Distinct hydrogen electrostatic binding sites at the $\mathrm{C}=\mathrm{C}$ bond of the imidazole ligand and at the center channel of the six member ring contribute to $\mathrm{H}_{2}$ adsorption in ZIF-8 [30,31]. The temperature dependent permeation data for $\mathrm{H}_{2}$ confirm lower activation energy for diffusion than heat of adsorption for $\mathrm{H}_{2}$ in $\mathrm{ZIF}-8$.

Figure 5 graphically illustrates the ZIF-8 membrane permeance and separation factor for a binary 50:50 $\mathrm{H}_{2} / \mathrm{CO}_{2}$ feed as a function of temperature ranging from $25-300^{\circ} \mathrm{C}$. Between $25-$ $250^{\circ} \mathrm{C}$, the permeance for both $\mathrm{H}_{2}$ and $\mathrm{CO}_{2}$ decreases as a function of increasing temperature, which is similar to the temperature dependency of pure gas permeance. Gas permeation through ZIF-8 membranes follows the solution-diffusion mechanism [23]; the permeability of a permeating gas is the product of the diffusivity and solubility (or adsorption constant). Due to the similarity in single and binary gas permeance behavior, we map the ideal solution-diffusion model to the binary mixture to describe the phenomena observed. The kinetic diameters of $\mathrm{H}_{2}$ and $\mathrm{CO}_{2}$ are 0.29 and $0.33 \mathrm{~nm}$ respectively, each just slightly smaller than the $0.34 \mathrm{~nm}$ crystallographic pore aperture of ZIF-8. However, due to framework flexibility and imidazole substituent displacement, the ZIF-8 pore configuration inhibits strict molecular sieving cut offs before $0.42 \mathrm{~nm}$ [32]. Framework flexibility/displacement results in large intracrystalline diffusivities for $\mathrm{H}_{2}\left(9.4 \times 10^{-5} \mathrm{~cm}^{2} / \mathrm{s}\right)$ and $\mathrm{CO}_{2}\left(1.7 \times 10^{-6} \mathrm{~cm}^{2} / \mathrm{s}\right)$ in $\mathrm{ZIF}-8$ [22]. $\mathrm{H}_{2} / \mathrm{CO}_{2}$ diffusive selectivity in ZIF-8 is 55, however, the adsorption equilibrium constant for $\mathrm{CO}_{2}$ in $\mathrm{ZIF}-8$ (0.56 $\mathrm{mmol} / \mathrm{g}$. bar $)$ is much larger than that for $\mathrm{H}_{2}(0.039 \mathrm{mmol} / \mathrm{g}$. bar $)$ [22] at room temperature. This 
gives adsorptive selectivity of about $1 / 15$ for $\mathrm{H}_{2} / \mathrm{CO}_{2}$. The product of the $\mathrm{H}_{2} / \mathrm{CO}_{2}$ adsorptive and diffusive selectivites determines the ideal $\mathrm{H}_{2} / \mathrm{CO}_{2}$ permselectivity which is 3.7 and consequently is the same value as the separation factor obtained at room temperature during the binary experiment. The binary $\mathrm{H}_{2} / \mathrm{CO}_{2}$ separation factor is diffusion controlled or increases with respect to temperature between $25-225^{\circ} \mathrm{C}$ because of the relatively weaker adsorptive/stronger diffusive dependence for $\mathrm{H}_{2}$ permeance as compared to that for $\mathrm{CO}_{2}$ permeance.

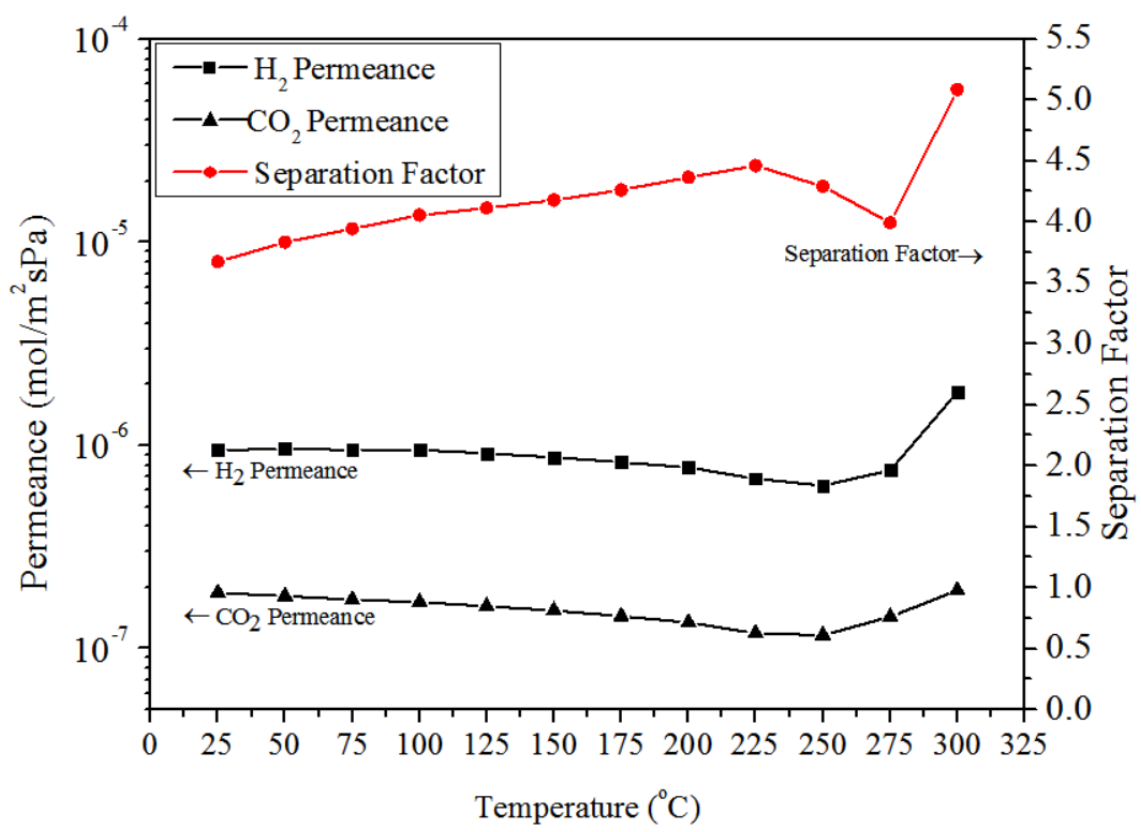

Figure 5. ZIF-8 membrane binary $\mathrm{H}_{2} / \mathrm{CO}_{2}$ permeance and separation factor as a function of temperature from $25-300^{\circ} \mathrm{C}$

Figure 6 presents the transient weight change of ZIF-8 crystals under 50:50 $\mathrm{H}_{2} / \mathrm{CO}_{2}$ atmosphere using a temperature profile identical to the heating protocol utilized during the binary gas separation measurements shown in Figure 5. A dramatic rate of weight decrease at the onset of data collection, attributable to the loss of solvent molecules and unreacted organic moieties in trapped within ZIF-8 microcavities [11] is observed. Between $50-250^{\circ} \mathrm{C}$ the weight loss is extremely slow $(0.04 \mathrm{wt} \% / \mathrm{hr})$ and small (less than $2 \%)$. This indicates that the large 
change observed for $\mathrm{H}_{2}$ and $\mathrm{CO}_{2}$ gas permeances (33-38\%) in the membrane separation experiments between $50-250^{\circ} \mathrm{C}$ are not caused by membrane structural changes during the temperature dependent separation experiments, and confirms that the the temperature dependence of gas permeance and separation factor shown in Figure $\mathbf{5}$ is determined by the temperature dependence of diffusivity and solubility of the mixture at temperatures between 25 $250^{\circ} \mathrm{C}$.

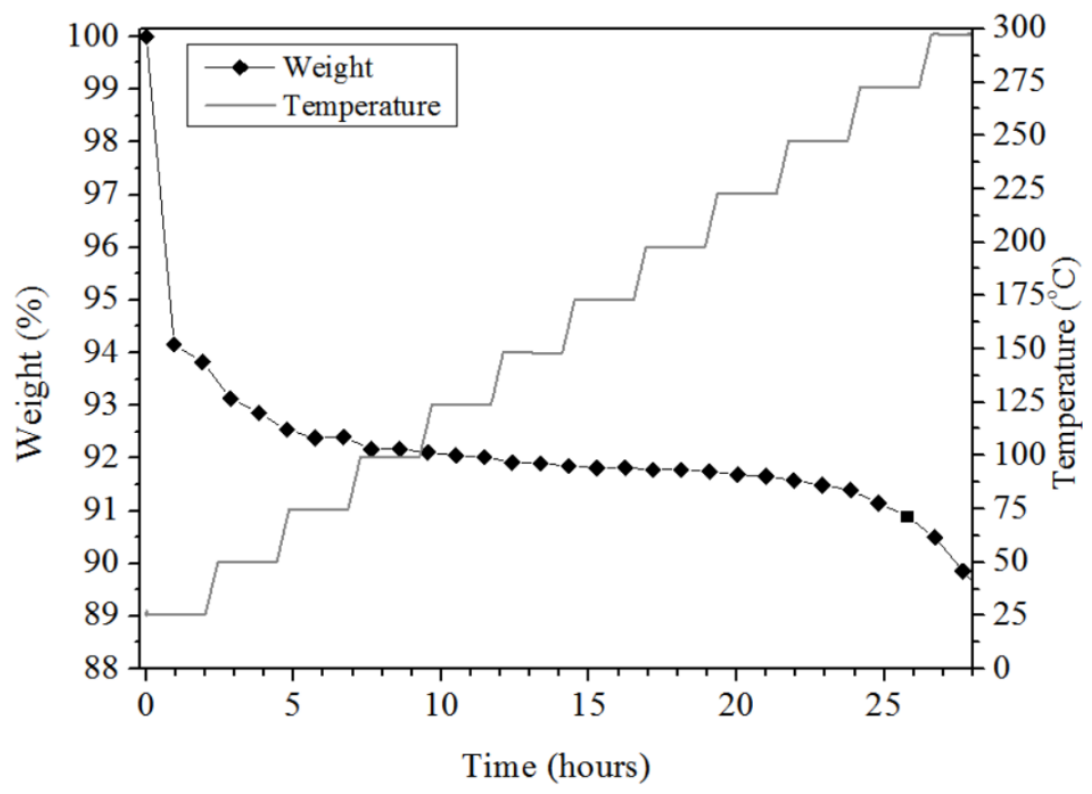

Figure 6. TGA weight decomposition profile of ZIF-8 crystals using a temperature profile and $\mathrm{H}_{2} / \mathrm{CO}_{2}$ atmosphere identical to temperature dependent permeation experiment

The mixture feed permeance temperature dependences for ZIF-8 membranes are quite different from the mixture permeation for microporous MFI zeolite membranes. MFI zeolite membranes have been substantially studied for $\mathrm{H}_{2} / \mathrm{CO}_{2}$ separations and provide an interesting comparison to ZIF-8 membranes. Both materials contain zeolitically-structured crystalline micropores, yet present very disparate $\mathrm{H}_{2} / \mathrm{CO}_{2}$ separation characteristics as a function of temperature. During binary $\mathrm{H}_{2} / \mathrm{CO}_{2}$ permeation in MFI zeolite membranes, $\mathrm{H}_{2}$ permeance 
increases while $\mathrm{CO}_{2}$ permeance decreases as a function of increasing temperature, though pure gas permeance for both gasses decrease with increasing temperature $[33,34]$.

It is known that diffusivity in micropores is mainly determined by the ratio of the permeating gas molecular diameter to the effective pore diameter, $\lambda=d_{m} / d_{p}(=0.69$ and 0.79 for $\mathrm{H}_{2}$ and $\mathrm{CO}_{2}$ in ZIF-8) and the activation energy for diffusion sharply increases or diffusivity decreases with increasing $\lambda$ when it approaches 1 (permeating molecule size close to the membrane pore size) [34]. The diffusivity for $\mathrm{H}_{2}$ and $\mathrm{CO}_{2}$ in MFI zeolite is respectively about $2 \times 10^{-4}$ and $3 \times 10^{-5} \mathrm{~cm}^{2} / \mathrm{s}$, much larger that in ZIF-8 $\left(9.4 \times 10^{-5} \mathrm{~cm}^{2} / \mathrm{s}\right.$ and $\left.1.7 \times 10^{-6} \mathrm{~cm}^{2} / \mathrm{s}\right)$ due to larger pore size for MFI zeolite (about $0.55 \mathrm{~nm}$ ). The ratio of the diffusivity for $\mathrm{H}_{2}$ to $\mathrm{CO}_{2}$ for MFI zeolite (about 6) is also much smaller than that for ZIF-8 (about 55). Due to smaller differences in diffusivities for these two gases in MFI zeolite membranes, the presence of the strongly adsorbed $\mathrm{CO}_{2}$ in the mixture feed has a larger effect on the diffusivity of lightly adsorbed $\mathrm{H}_{2}$, reducing its permeance at low temperatures while $\mathrm{CO}_{2}$ adsorption is enhanced. This explains the opposite temperature dependence of $\mathrm{H}_{2}$ permeance within the mixture feed as compared to the pure $\mathrm{H}_{2}$ permeance [34]. For ZIF-8 membranes, such an adsorption induced effect in the mixture feed is insufficient to reverse the diffusion controlled selectivity that would give an opposite permeance temperature dependence for $\mathrm{H}_{2}$ as compared to the single gas feed.

From $250-275^{\circ} \mathrm{C}$, the permeance behavior for both $\mathrm{H}_{2}$ and $\mathrm{CO}_{2}$ inverts or increases as a function of increasing temperature, as shown in Figure 5. At such high temperatures, adsorption becomes negligible thus permeance is essentially controlled by diffusivity, which increases with temperature. The permeance selectivity decreases with temperature between $225-275^{\circ} \mathrm{C}$ because the change in diffusivity for $\mathrm{CO}_{2}$ with a larger activation energy, increases more with temperature as compared to $\mathrm{H}_{2}$. Beyond $275^{\circ} \mathrm{C}$ the $\mathrm{H}_{2} / \mathrm{CO}_{2}$ separation factor displays a step 
change from 4.0 to 5.1. TGA data in Figure 6 shows with a temperature increase from 275 to $300^{\circ} \mathrm{C}$ the membrane experiences a greater magnitude weight loss $(2 \%)$ than previously experienced due to a faster decomposition rate $(0.1-0.3 \mathrm{wt} \% / \mathrm{hr})$. As will be discussed later, this indicates a structural change in ZIF-8 material which is most likely responsible for altering the transport mechanism previously governing $\mathrm{H}_{2} / \mathrm{CO}_{2}$ permeability and selectivity.

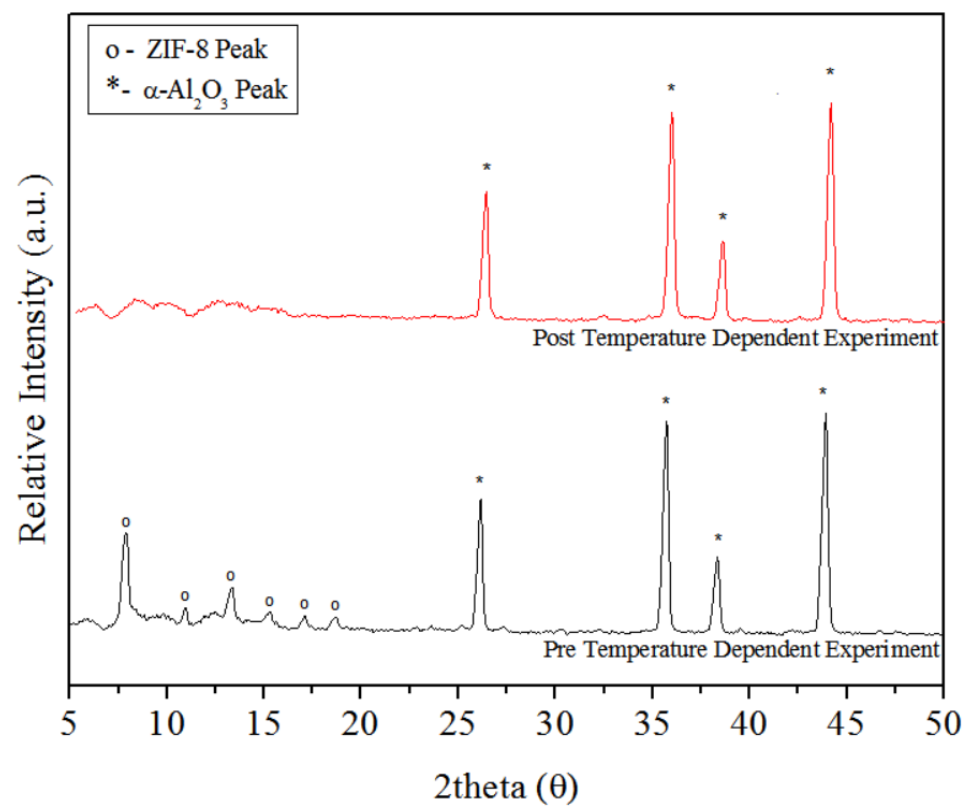

Figure 7. ZIF-8 membrane XRD patterns before and after binary $\mathrm{H}_{2} / \mathrm{CO}_{2}$ temperature dependent $\left(25-300^{\circ} \mathrm{C}\right)$ permeance study

Figure 7 shows XRD patterns of the ZIF-8 membrane before and after the temperature dependent membrane experiment shown in Figure 5. Structural changes in the ZIF-8 membrane thin film are evidenced through the disappearance of all peaks associated with the ZIF-8 morphology. This finding is corroborated by corresponding SEM images of the ZIF-8 membrane after the temperature dependent experiment shown in Figure 8. The micrographs present a new structure bearing an amorphous topology similar to that of a polymeric or carbon molecular sieve 
membrane upon analysis at low magnification [35]. Greater magnification shows evidence of a transformed, lacerated surface with slightly raised portions resembling extremely faint, flattened/decomposed ZIF-8 rhombic dodecahedral crystals.
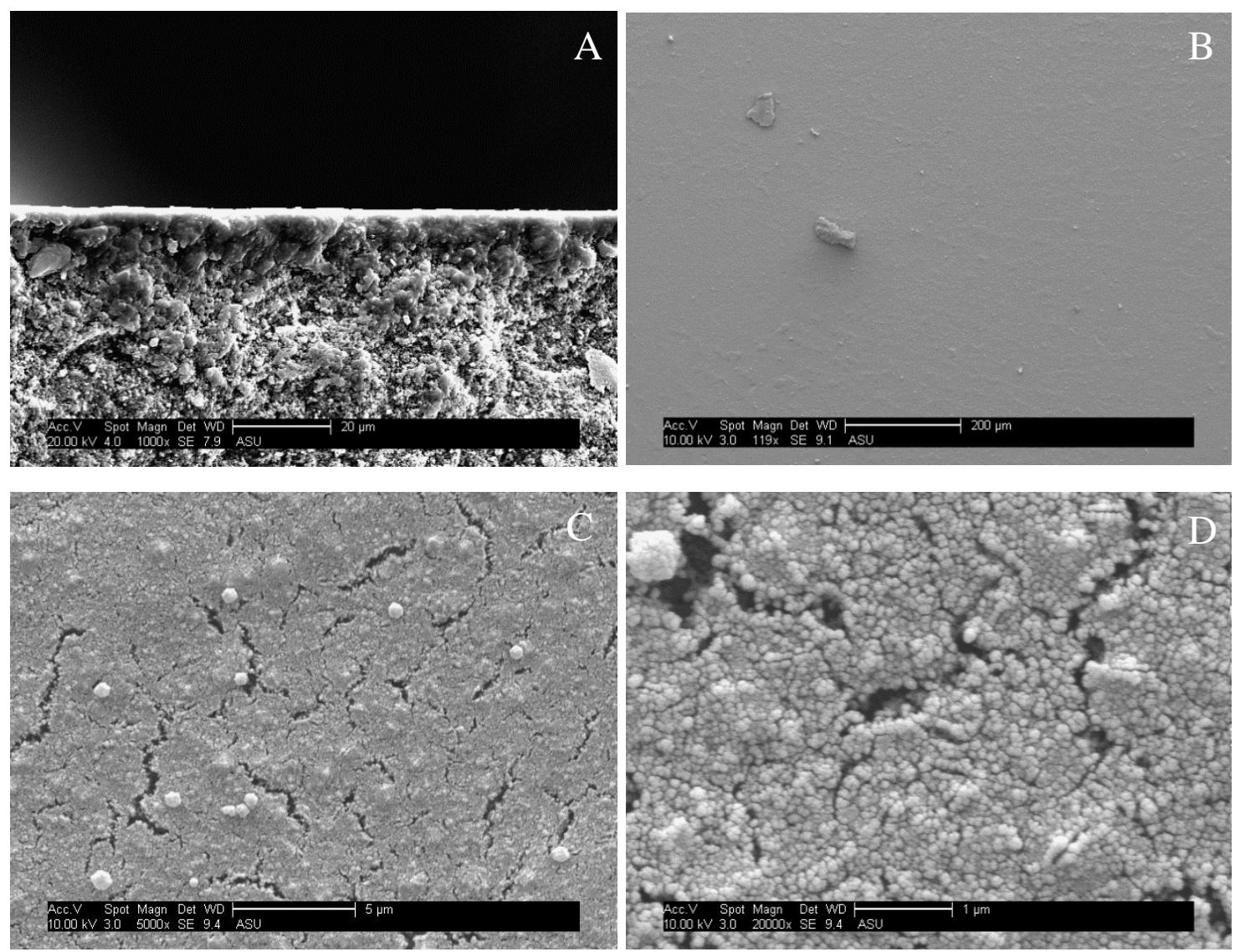

Figure 8. ZIF-8 membrane SEM micrographs after temperature dependent $\left(25-300^{\circ} \mathrm{C}\right)$ binary $\mathrm{H}_{2} / \mathrm{CO}_{2}$ experiment: cross-section (A), top views (B-D)

ZIF-8 crystal decomposition from the analogous TGA experiment is also corroborated by pre and post experimental XRD patterns in Figure 9 which show a decrease in peak intensities at the characteristic ZIF-8 $2 \theta$ values. It is duly noted that only a partial decrease in XRD pattern intensity ( $56 \%$ decrease in (011) peak intensity) was experienced after the ZIF-8 powder temperature programmed TGA study. In contrast, the analogous membrane permeance 
test showed complete elimination of all peaks associated with ZIF-8. A significantly larger amount of material must be consumed before crystallinity is eliminated in a $15 \mathrm{mg}$ ZIF-8 powder sample as compared to a ZIF-8 film $2.5 \mu \mathrm{m}$ in thickness and $22 \mathrm{~mm}$ in diameter which weighs around $1.08 \mathrm{mg}$ and can explain the differences in x-ray diffraction patterns.

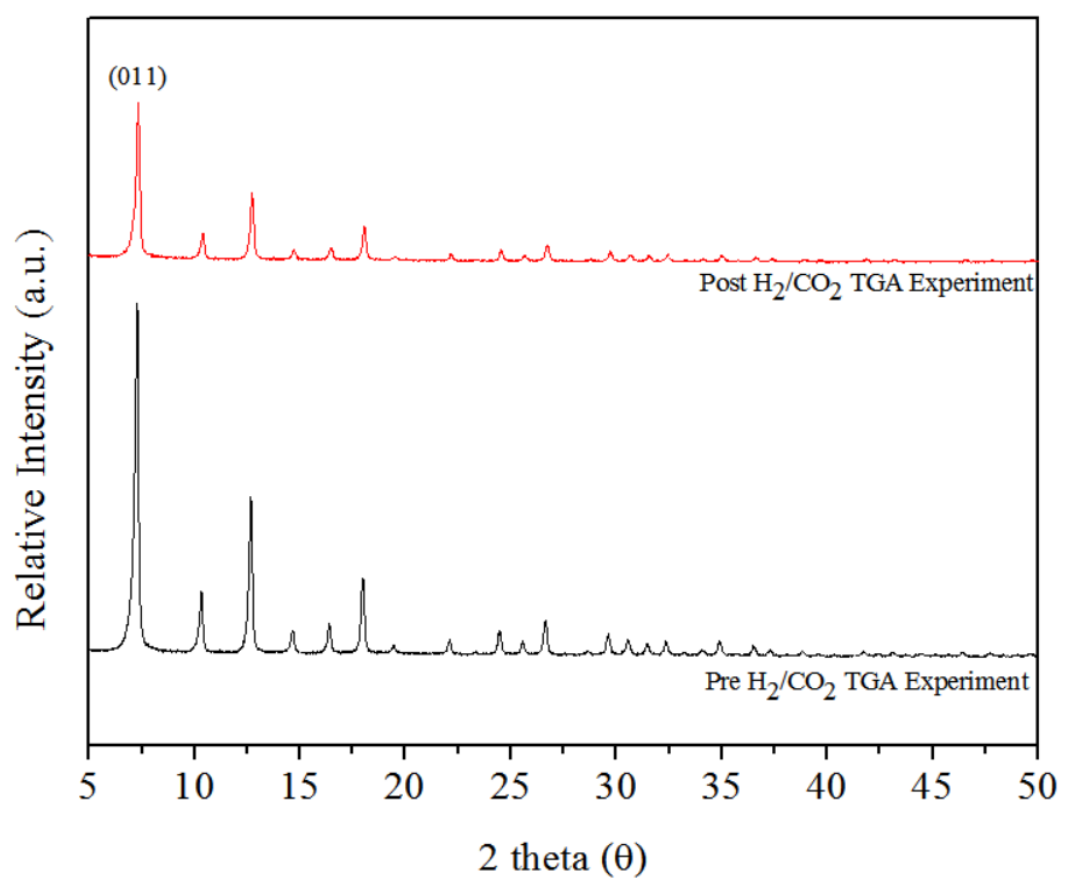

Figure 9. ZIF-8 powder XRD patterns before and after $\mathrm{H}_{2} / \mathrm{CO}_{2}$ atmosphere temperature dependent $\left(25-300^{\circ} \mathrm{C}\right)$ TGA experiment

\subsection{Transient Separation Properties and ZIF-8 Membrane Structural Changes}

In the previously performed binary experiments the ZIF-8 membrane was subjected to each temperature for only 2.5 hours in a dynamic experiment over a 30 hour duration. To better understand and more carefully analyze the thermal stability of ZIF-8 membrane thin films, isothermal, transient, $50: 50 \mathrm{H}_{2} / \mathrm{CO}_{2}$ permeation experiments were conducted at temperatures of 50, 100 and $150^{\circ} \mathrm{C}$ for 24 hours enabling adequate bounds to be placed on ZIF- 8 membrane static thermal stability. The permeation results of each isothermal test are shown in Figure $\mathbf{1 0 .}$ 

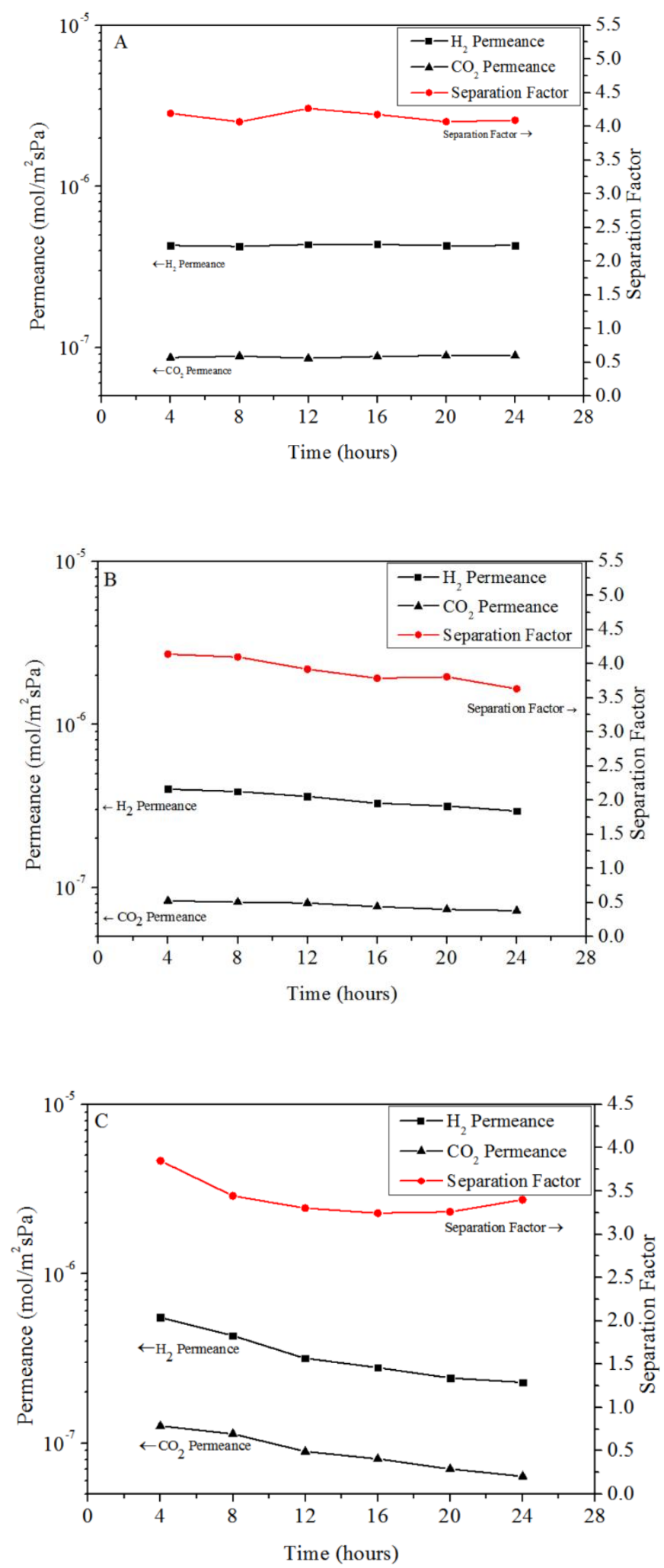

Figure 10. Transient profiles of $\mathrm{ZIF}-8$ membrane $\mathrm{H}_{2} / \mathrm{CO}_{2}$ mixture permeance and separation factor with respect to time at isothermal temperatures of (A) $50^{\circ} \mathrm{C}$, (B) $100^{\circ} \mathrm{C}$ and (C) $150^{\circ} \mathrm{C}(24$ hours) 
Qualitative analysis of the transient profiles suggest that the extent of decline in both $\mathrm{H}_{2}$ and $\mathrm{CO}_{2}$ permeances is intensified with respect to increasing isothermal temperature. Table 2 tabulates and quantifies the percentage decreases in $\mathrm{H}_{2} / \mathrm{CO}_{2}$ permeances and separation factors during the isothermal transient experiments.

Table 2. ZIF-8 Membrane Percentage Change in $\mathrm{H}_{2} / \mathrm{CO}_{2}$ Separation Performance and XRD/FTIR Peak Intensity Ratios before and after Low Temperature Transient Tests

\begin{tabular}{|c|c|c|c|c|c|c|}
\hline $\begin{array}{c}\text { Transient } \\
\text { Experiment }\end{array}$ & $\begin{array}{l}\% \text { Decrease } \\
\text { in } \mathrm{H}_{2} \\
\text { Permeance }\end{array}$ & $\begin{array}{c}\% \text { Decrease } \\
\text { in } \\
\mathrm{CO}_{2} \\
\text { Permeance }\end{array}$ & $\begin{array}{c}\% \text { Decrease } \\
\text { in } \mathrm{CO}_{2} \\
\text { Separation } \\
\text { Factor }\end{array}$ & $\begin{array}{c}\text { ZIF-8 }(011) \\
\text { Peak to } \alpha- \\
\mathrm{Al}_{2} \mathrm{O}_{3}(012) \\
\text { Peak XRD } \\
\text { Intensity } \\
\text { Ratio } \\
\text { Before/After } \\
\text { Transient } \\
\text { Experiment }\end{array}$ & $\begin{array}{c}\text { Experimenta } \\
1 \text { ZIF-8 } \\
\text { Membrane/ } \\
\text { As- } \\
\text { synthesized } \\
\text { ZIF-8 } \\
\text { Membrane } \\
\delta \mathrm{CH}_{3} \text { FTIR } \\
\text { Band } \\
\text { Intensity } \\
\end{array}$ & $\begin{array}{c}\text { Experimenta } \\
1 \text { ZIF-8 } \\
\text { Membrane/ } \\
\text { As- } \\
\text { synthesized } \\
\text { ZIF-8 } \\
\text { Membrane } \\
\text { C=N FTIR } \\
\text { Band } \\
\text { Intensity } \\
\end{array}$ \\
\hline & & & & $1.20 / 1.26$ & 1.06 & 1.00 \\
\hline & & & & & & 1. \\
\hline $150^{\circ} \mathrm{C}$ & 58.6 & 49.6 & 11.6 & $1.69 / 0.95$ & 0.67 & 0.68 \\
\hline
\end{tabular}

At $50^{\circ} \mathrm{C}$ both $\mathrm{H}_{2}$ and $\mathrm{CO}_{2}$ permeances and separation factor remain essentially constant over the 24 hour duration. However, at $100{ }^{\circ} \mathrm{C} 26.5 \%$ and $12.2 \%$ decreases in $\mathrm{H}_{2}$ and $\mathrm{CO}_{2}$ permeances are observed. The greater extent of decline in $\mathrm{H}_{2}$ permeance as compared to that of $\mathrm{CO}_{2}$ causes the separation factor to decrease by $12.9 \%$ over the 24 hour period. At an isothermal temperature of $150^{\circ} \mathrm{C}$, more dramatic decreases in $\mathrm{H}_{2}$ and $\mathrm{CO}_{2}$ permeances are incurred. The transient permeance profiles obtained during the $150^{\circ} \mathrm{C}$ experiment indicate that the percentage declines in $\mathrm{H}_{2}$ and $\mathrm{CO}_{2}$ permeances were 2 and 4 times greater than those observed during the $100^{\circ} \mathrm{C}$ test respectively. 
It is possible that local defects at un-saturated $\mathrm{Zn}$ sites of the ZIF-8 secondary building units might have been created during permeance tests and caused performance instability [36]. It is also possible that the $\mathrm{CO}_{2}$ chemisorption phenomena previously observed by $\mathrm{Xu}$ et al. [37] during transient $\mathrm{H}_{2} / \mathrm{CO}_{2}$ tests occurred, however it would seem that the temperature dependency of the $\mathrm{CO}_{2}$ /imidazole reaction is greater in this study and may be due to differences in membrane crystallinity. Xu et al. observed the postulated chemisorption phenomena at room temperature [37], whereas in this study, comparable $\mathrm{H}_{2} / \mathrm{CO}_{2}$ decreases were not observed until performing isothermal tests at $150^{\circ} \mathrm{C}$.

Membrane characterization can enable further insight into the physical changes of the membrane structure and further explain the permeation phenomena observed. Figure 11 presents comparative pre and post transient experiment XRD patterns and changes in XRD relative pattern intensity are quantitatively described in Table $\mathbf{2}$ which tabulates ZIF-8 membrane (011) plane intensity with respect to $\alpha$ - alumina (012) plane intensity before after the 24 hour isothermal transient experiments studied at 50,100 and $150^{\circ} \mathrm{C}$ respectively. XRD patterns corroborate preservation of the ZIF-8 phase after each isothermal experiment. After isothermal 50 and $100^{\circ} \mathrm{C}$ experiments, ZIF- 8 to $\alpha$-alumina peak intensity is essentially comparable or even slightly increased due to slight changes in ZIF-8 crystal dimensions through removal of guest solvent molecules during permeation. However, decreases in the relative peak intensity are significant for the sample tested at $150^{\circ} \mathrm{C}$ and indicates that ZIF-8 degradation or crystallinity elimination occurred over the 24 hour isothermal experiment. 

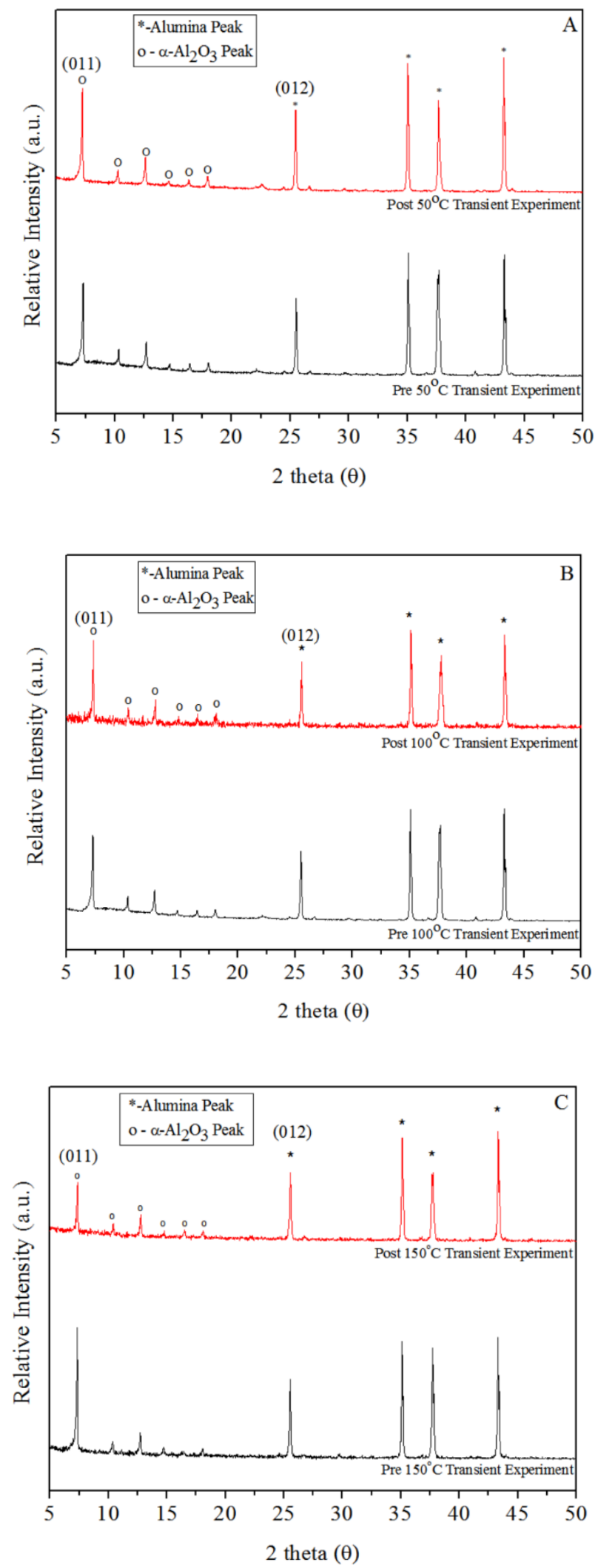

Figure 11. ZIF- 8 membrane XRD patterns before and after 24 hour binary $\mathrm{H}_{2} / \mathrm{CO}_{2}$ separation isothermal study at (A) $50^{\circ} \mathrm{C}$, (B) $100^{\circ} \mathrm{C}$ and (D) $150^{\circ} \mathrm{C}$ 

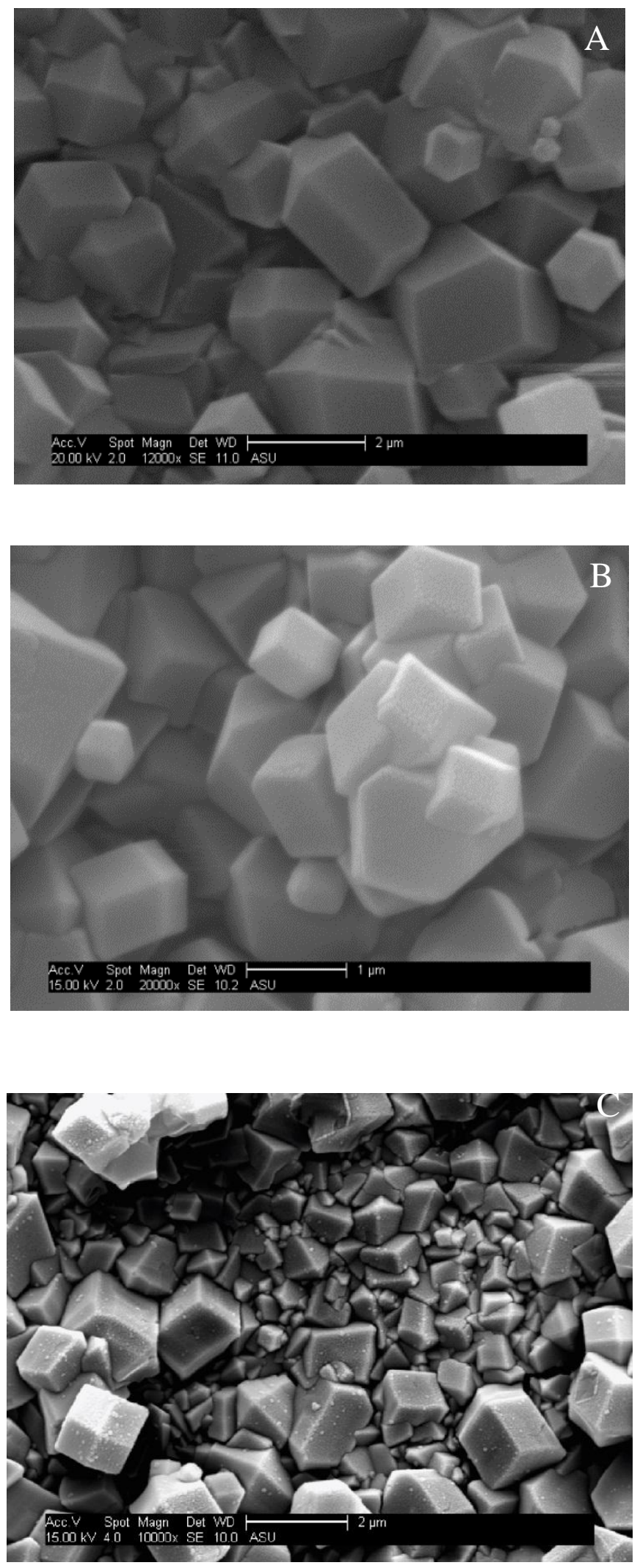

Figure 12. SEM micrographs of ZIF- 8 membranes post binary $\mathrm{H}_{2} / \mathrm{CO}_{2} 24$ hour transient separation studies at isothermal temperatures of (A) $50^{\circ} \mathrm{C},(\mathrm{B}) 100^{\circ} \mathrm{C}$ and (C) $150^{\circ} \mathrm{C}$ 
Upon analysis of SEM micrographs, the crystal morphology and textural features of the membranes held at 100 and $50^{\circ} \mathrm{C}$ remain intact (Figures 12 A\&B). However, intermittent defects are expressed along the faces and edges of the rhombic dodecahedral crystals composing the ZIF-8 membrane held at $150^{\circ} \mathrm{C}$ (Figure $12 \mathrm{C}$ ) and may illustrate ZIF material precipitating out from the ZIF-8 polycrystalline network crystals. The results found in SEM micrographs and XRD analysis complement each other and the permeance data well. The greatest amount of crystal destruction and permeance performance decreases were observed during the $150^{\circ} \mathrm{C}$ isothermal transient experiment, but at lower temperatures, comparatively little to no changes in crystallinity, external crystal morphology and performance were observed.

The data shown in Figures $\mathbf{7}$ and $\mathbf{8}$ suggest more prominent changes in the ZIF-8 thin film structure occur at higher temperatures. To further understand structural changes in the ZIF-8 framework at high temperature, a transient separation test was conducted on a separate ZIF-8 membrane at $300^{\circ} \mathrm{C}$ for 24 hours. Figure 13 graphically depicts $\mathrm{H}_{2} / \mathrm{CO}_{2}$ permeance and separation factor during the high temperature isothermal transient experiment. Between 0-4 hours, a sharp decrease in $\mathrm{H}_{2}$ and $\mathrm{CO}_{2}$ permeances with a resulting increase in $\mathrm{H}_{2} / \mathrm{CO}_{2}$ separation factor is observed. After 4 hours, the $\mathrm{H}_{2}$ and $\mathrm{CO}_{2}$ permeances both increase and reach steadystate values after 12 total hours of permeation time and a separation factor of $\sim 3.7$ is sustained for the duration of the study. After 12 hours, we prognosticate that a stable permeance and separation factor is indicative of forming a structure that is kinetically or possibly thermodynamically stable at $300^{\circ} \mathrm{C}$. 


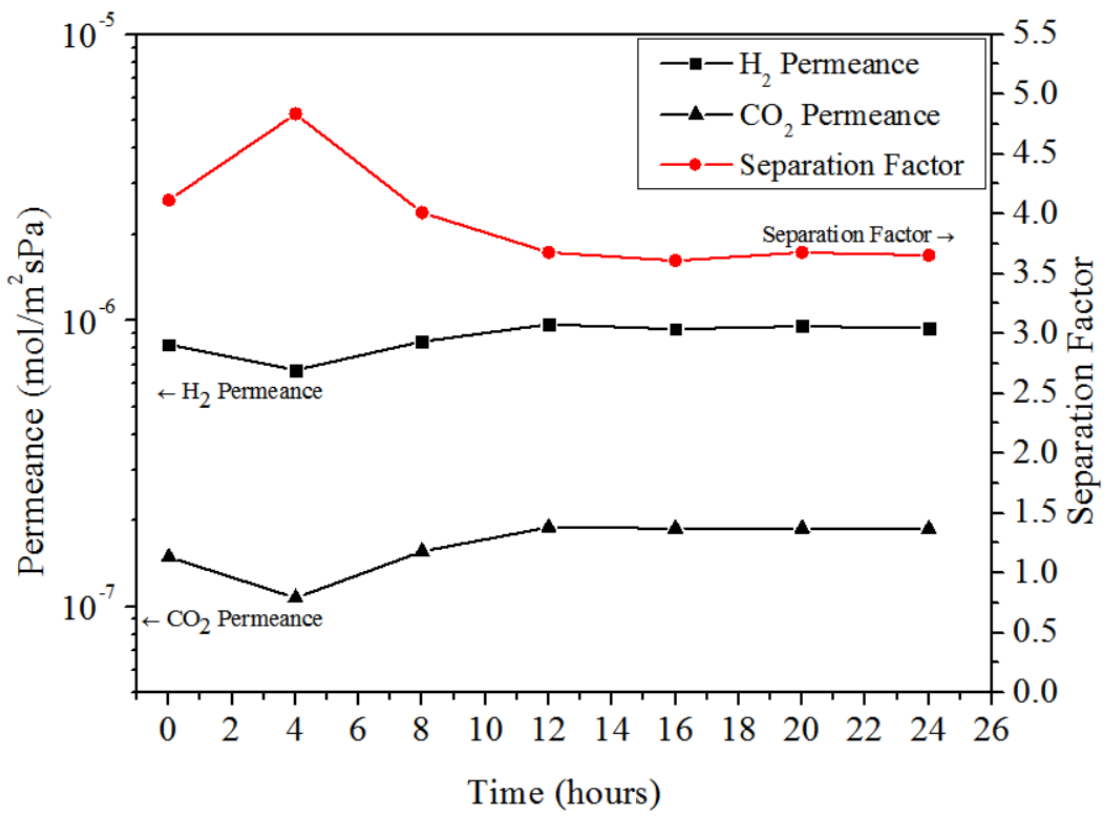

Figure 13. ZIF-8 membrane $\mathrm{H}_{2} / \mathrm{CO}_{2}$ mixture permeance and separation factor with respect to time during $300^{\circ} \mathrm{C}$ isothermal transient experiment ( 24 hours)

Post experimental XRD patterns and SEM micrographs of the membrane utilized in the $300^{\circ} \mathrm{C}$ isothermal transient experiment are depicted in Figures 14 \& 15 . The disappearance of the XRD peaks associated with the ZIF-8 phase again indicates formation of an amorphous structure. SEM images show that the surface of the ZIF-8 membrane after subjection to thermal stress at $300^{\circ} \mathrm{C}$ still retains crystal facets but with less defined, eroded faces. As noted from Figure 13, the steady-state $\mathrm{H}_{2}$ and $\mathrm{CO}_{2}$ permeances are slightly greater than the initial rates observed at 0 hour, and although the separation factor is lower than initially observed, the newly formed amorphous material is still able to separate $\mathrm{H}_{2}$ from $\mathrm{CO}_{2}$. It is possible that the newly formed amorphous membrane remains microporous with small pores enabling $\mathrm{H}_{2} / \mathrm{CO}_{2}$ separation. This is similar to amorphous carbon molecular sieve membranes developed from 
thermosetting polymers through pyrolysis [38]. The permeance changes shown in Figure 13 reflect changes in pore size, porosity and tortuosity during the heat-treatment.

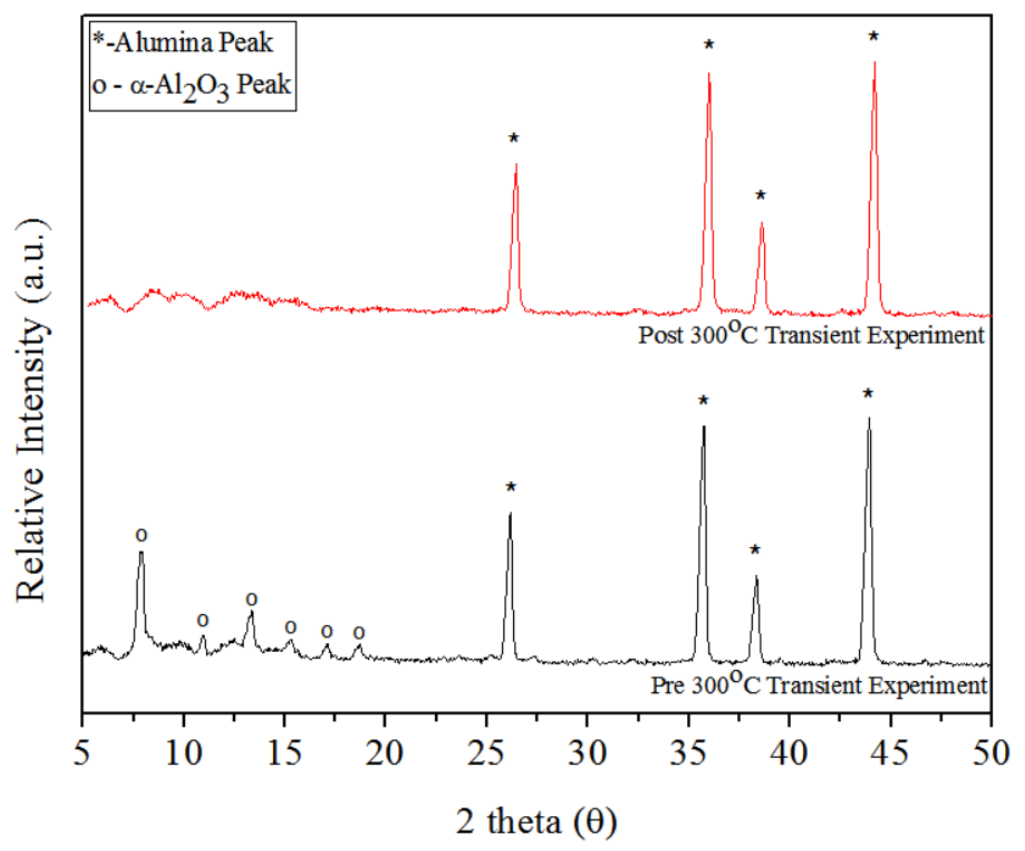

Figure 14. ZIF-8 membrane XRD pattern before and after 24 hour binary $\mathrm{H}_{2} / \mathrm{CO}_{2}$ separation isothermal study at $300^{\circ} \mathrm{C}$

Figure 16 illustrates comparative IR spectral bands of experimental membranes. The fresh, as-synthesized ZIF-8 membrane transmittance bands are in good agreement with those reported by Ordonez et al. [39] and $\mathrm{Hu}$ et al. [40]. IR bands between $900-1350 \mathrm{~cm}^{-1}$ are associated with in-plane bending modes of the imidazole ring. The intense bands between 1350$1500 \mathrm{~cm}^{-1}$ are concomitant with entire imidazole ring stretching and the small peaks indicated at $1384 \mathrm{~cm}^{-1}$ and $1584 \mathrm{~cm}^{-1}$ correspond to $-\mathrm{CH}_{3}$ bending and $\mathrm{C}=\mathrm{N}$ stretching modes respectively. Due to spectral saturation, $\mathrm{Zn}-\mathrm{N}$ modes usually present at $421 \mathrm{~cm}^{-1}$ are not shown. Table 2 additionally highlights relative IR spectral intensities of the $-\mathrm{CH}_{3}$ and $\mathrm{C}=\mathrm{N}$ bonds of isothermally tested membrane thin film surfaces with respect to an as-synthesized membrane for semi-quantitative relative magnitude analysis. 

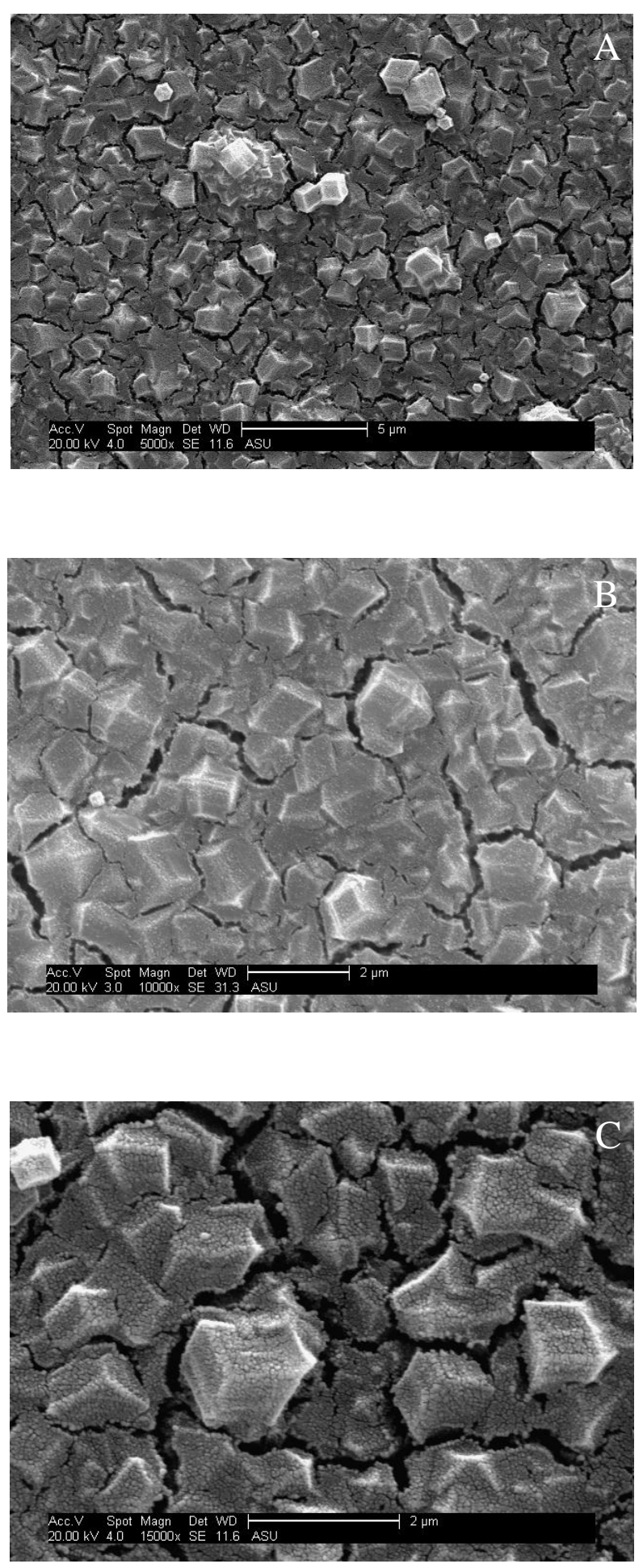

Figure 15. ZIF-8 membrane SEM micrographs post $300^{\circ} \mathrm{C}$ isothermal transient binary $\mathrm{H}_{2} / \mathrm{CO}_{2}$ experiment: 5,000X magnification (A), 10,000X magnification (B) and 15,000X magnification (C) 


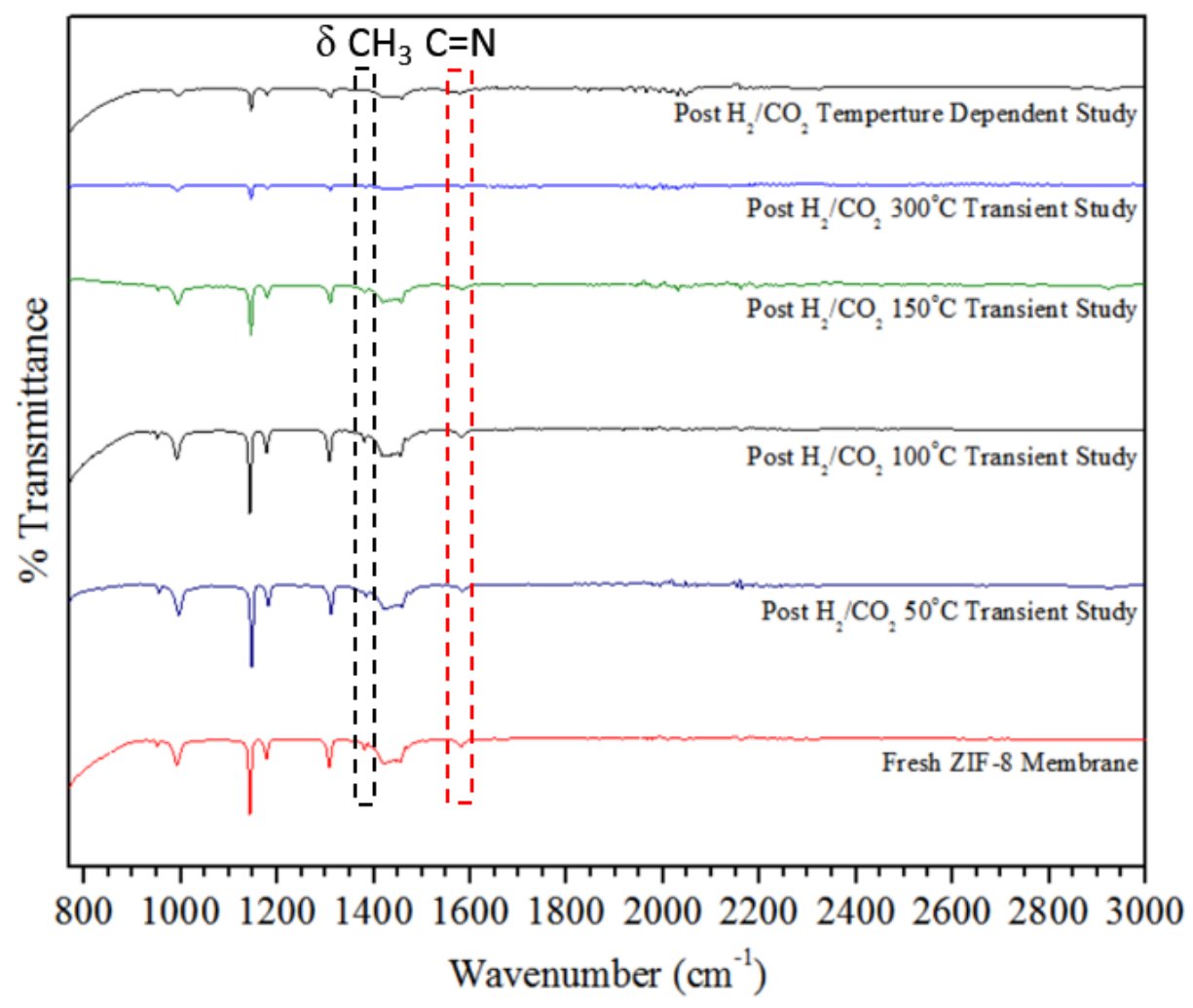

Figure 16. FTIR spectra of ZIF-8 membranes held in $\mathrm{H}_{2} / \mathrm{CO}_{2}$ atmosphere after $25-300^{\circ} \mathrm{C}$ temperature dependent experiment and 24 hour transient isothermal experiments at 50, 100, 150, and $300^{\circ} \mathrm{C}$ respectively all relative to as-synthesized (fresh) ZIF-8 membrane spectrum

Visual comparison of post experimental low temperature isothermal IR spectra to that of the as-synthesized spectra indicate preservation of imidazole ring physical properties after permeation at 50 and $100^{\circ} \mathrm{C}$. Further detailed evidence of bond preservation is evidenced by the relative intensity data in Table 2 which show comparable spectral intensities before and after the 50 and $100^{\circ} \mathrm{C}$ experiments. In contrast, relative intensity values at the corresponding spectral bands for the membrane isothermally tested at $150^{\circ} \mathrm{C}$ indicate depletion of $\mathrm{CH}_{3}$ and $\mathrm{C}=\mathrm{N}$ bonds. The results found in the FTIR experiments complement the SEM/XRD data well and indicate that alumina supported ZIF-8 thin films preserve full crystallinity and structural integrity at temperatures below $150^{\circ} \mathrm{C}$. 
At greater temperatures, significant, definitive changes in $\mathrm{C}=\mathrm{N}$, methyl group and entire ring bonding occurred and is evidenced by considerable broadening of the corresponding spectral modes for the membranes isothermally tested at $300^{\circ} \mathrm{C}$ and utilized in the temperature dependent test. Specific evidence of $\mathrm{C}=\mathrm{N}$ bond breaking and demethylation observed in the high temperature spectra agree with the results observed by Lin and James [15] who postulated that a heterogeneous imidazole-Zn-azirine partially carbonized ZIF-8 structure is formed through a sequence of thermolytic decomposition reactions after thermally annealing ZIF-8 crystals at $300^{\circ} \mathrm{C}$ for 20 hours in $\mathrm{H}_{2} / \mathrm{CO}_{2}$ atmosphere. For ZIF-8 crystal decomposition in $\mathrm{H}_{2} / \mathrm{CO}_{2}$ environment at $300^{\circ} \mathrm{C}$ for 20 hours the following decomposition reaction equation was proposed [15]:

$\mathrm{Zn}\left(\mathrm{C}_{4} \mathrm{H}_{5} \mathrm{~N}_{2}\right)_{2}+$ heat $\rightarrow \mathrm{C}_{4} \mathrm{H}_{5} \mathrm{~N}_{2}-\mathrm{Zn}-\mathrm{C}_{2} \mathrm{H}_{2} \mathrm{~N}+$ Gaseous Products

where the Zn complex on the reactants side of Reaction A represents a single building block of ZIF-8 consisting of a zinc cation coordinating two imidazole ligands. After sustained thermal stress at the corresponding temperature it is postulated that the average solid structure remaining (product) after ZIF-8 crystal decomposition is a $\mathrm{Zn}$ cation coordinated to the $\mathrm{N}$ atom of a fully intact 2-methylimidazole ligand and the $\mathrm{N}$ atom of an azirine molecule. Differences in ZIF-8 material concentration between a bulk sample of ZIF-8 crystals and an alumina supported ZIF-8 thin film invalidate a 1-to-1 comparison of FTIR spectra, however we postulate that a similar structure is formed upon decomposition of ZIF-8 membranes.

The morphology changes shown in the post experimental SEM images of Figures 8 and 15 can be explained in part by the partial carbonization process described in Reaction A. Upon 
sustained thermal stress of ZIF-8 membrane crystals at $300^{\circ} \mathrm{C}$, demethylation and release of framework $\mathrm{N}$ atoms from deteriorated $\mathrm{C} / \mathrm{N}$ and $\mathrm{Zn}-\mathrm{N}$ bond destruction each occur to form the postulated imidazole-Zn-azirine structure. Although $\mathrm{Zn}-\mathrm{N}$ spectral bands are not shown, $\mathrm{Zn}$ must lose coordination with $\mathrm{N}$ in order to form the postulated imidazole-Zn-azirine structure. We deduce that if $\mathrm{C}=\mathrm{N}$ and $-\mathrm{CH}_{3}$ bonds are broken, $\mathrm{Zn}-\mathrm{N}$ bonds must also break as they are comparatively the weakest bond in the ZIF-8 structure [41]. In the case of ZIF-8 membrane crystals, partial carbonization and loss of coordination at $\mathrm{Zn}-\mathrm{N}$ nodes which act as major structural supports most likely induces framework collapse to form eroded crystals which eventually reduce to a partially carbonized membrane surface topology that is visibly flat or presents eroded crystal facets.

The structural collapse noted in this study somewhat contrasts the phenomena observed when thermally treating loosely packed ZIF-8 crystalline powders. In our previous work [15], ZIF-8 crystalline powders were treated isothermally at $300^{\circ} \mathrm{C}$ in $\mathrm{H}_{2} / \mathrm{CO}_{2}$ atmosphere for 20 hours in a TGA experiment analogous to the $300^{\circ} \mathrm{C}$ transient membrane experiment conducted in the current study. Comparative SEM characterization analyses before and after thermal treatment of ZIF-8 crystals illustrate particle growth through coarsening/Ostwald through ripening phenomena [15] and XRD pattern/FTIR spectral analyses from our previous work [15] show that ZIF-8 crystals retain a relatively greater amount of crystallinity/bond preservation as compared to membrane thin films decomposed under similar conditions. In this study, particle collapse occurs rather than particle coarsening and may allude to slight differences in microstructural changes that occur upon thermal treatment of ZIF-8 powders which present kinetic thermal stability up to $200^{\circ} \mathrm{C}$ versus ZIF- 8 membrane thin films which seem thermally stable below $150^{\circ} \mathrm{C}$. 
It has been noted in the literature that the thermomechanical compatibility [21,22] and acidity [42] of the membrane support plays a significant role in membrane thermal and hydrothermal stability respectively. Under hydrothermal conditions in the presence of $10 \mathrm{~mol} \%$ water vapor it was determined that the acidic nature of $\alpha$-alumina supports catalyzes hydrolysis reactions which enable protonation and subsequent deterioration of ZIF-7 and ZIF-8 material adhered on $\alpha$-alumina supports [42], however, under dry [42] and more mild humidity conditions (3 mol\% water vapor) [16], the support does not seem to initiate ZIF decomposition through protonating reactions. These findings enable deduction that support acidity does not play a significant role in ZIF stability under dry conditions.

During thermal annealing under dry conditions, ZIF-8 thin films are subjected to incongruent mechanical stresses as a result of differences in thermal expansion coefficients between the alumina support and the membrane structure [21]. The resulting thermomechanical stress possibly compromises the ZIF thin film bonds during thermal annealing. ZIF crystals do not experience the aforementioned thermomechanical stresses during TGA experiments. The additional stress mechanism induced during thermal annealing of alumina supported ZIF-8 membranes likely exacerbates framework instability upon static thermal treatment. High temperature static stability experiments directly comparing $\alpha$-alumina supported ZIF-8 membranes with and without thermomechanically stabilizing interlayers or supports with thermal expansion coefficients more similar to that of ZIF-8 may be a point for future study. Additionally, metal oxide supports of varying acidity that are thermomechanically compatible with ZIF-8 would enable an effective study on the influence of support acidity on ZIF-8 hydrothermal stability. 


\section{Conclusions}

The thermal stability of high quality ZIF-8 membranes was systematically studied in terms of material structure and separation characteristics in $\mathrm{H}_{2} / \mathrm{CO}_{2}$ atmosphere at high temperatures. Dynamic temperature dependent permeation experiments show that $\mathrm{H}_{2} / \mathrm{CO}_{2}$ permeance and selectivity adhere to the solution-diffusion model between $25-275^{\circ} \mathrm{C}$, however beyond $275^{\circ} \mathrm{C}$ it is postulated that an amorphous carbonized imidazole-Zn-azirine structure is formed. Static isothermal permeation tests more adequate for static stability determination, show that ZIF-8 membrane thin films maintain crystallinity/bond integrity and sustain separation performance over a 24 hour experimental duration at temperatures below $150^{\circ} \mathrm{C}$. However at temperatures of $150^{\circ} \mathrm{C}$ and greater, ZIF-8 membrane thin films incur increased amounts of thermally induced carbonization of the imidazole ligand with respect to increasing temperature. The extent of carbonization changes the pore structure of the ZIF-8 membrane, and hence $\mathrm{H}_{2} / \mathrm{CO}_{2}$ permeance and selectivity. Thermomechanically induced stresses are caused by differences in thermal expansion coefficients of ZIF- 8 membrane thin films and $\alpha$-alumina supports which likely compromise ZIF-8 membrane structural bonds and may account for differences in static thermal stability observed when comparing ZIF-8 thin films and ZIF-8 crystals which do not incur identical thermomechanical stresses upon thermal annealing.

\section{Acknowledgements}

This work was supported by the National Science Foundation through grant CBET1511005. We would like to thank our Lab Manager Mr. Fred Peña for his design and modification of the high temperature permeance cell utilized in this study. We gratefully 
acknowledge the use of facilities with the LeRoy Eyring Center for Solid State Science at Arizona State University.

\section{References}

[1] K.S. Park, Z. Ni, A.P. Côté, J.Y. Choi, R. Huang, F.J. Uribe-Romo, H.K. Chae, M. O'Keeffe, O.M. Yaghi, Exceptional chemical and thermal stability of zeolitic imidazolate frameworks, Proc. Natl. Acad. Sci. U. S. A. 103 (2006) 10186-10191. doi:10.1073/pnas.0602439103.

[2] B. Chen, Z. Yang, Y. Zhu, Y. Xia, Zeolitic imidazolate framework materials : recent progress in synthesis and applications, J. Mater. Chem. A. 2 (2014) 16811-16831. doi:10.1039/C4TA02984D.

[3] M.D. Allendorf, V. Stavila, Crystal engineering, structure-function relationships, and the future of metal-organic frameworks, CrystEngComm. 17 (2015) 229-246. doi:10.1039/C4CE01693A.

[4] Y. Ban, Y. Li, Y. Peng, H. Jin, W. Jiao, X. Liu, W. Yang, Metal-substituted zeolitic imidazolate framework ZIF-108: Gas-sorption and membrane-separation properties, Chem. Eur. J. 20 (2014) 11402-11409. doi:10.1002/chem.201402287.

[5] C. Zhang, W.J. Koros, Zeolitic Imidazolate Framework- Enabled Membranes: Challenges and Opportunities, J. Phys. Chem. Lett. 6 (2015) 3841-3849. doi:10.1021/acs.jpclett.5b01602.

[6] Y. Pan, Z. Lai, Sharp separation of C2/C3 hydrocarbon mixtures by zeolitic imidazolate framework-8 (ZIF-8) membranes synthesized in aqueous solutions, Chem. Commun. 47 (2011) 10275-10277. doi:10.1039/c1cc14051e.

[7] H. Bux, A. Feldhoff, J. Cravillon, M. Wiebcke, Y.S. Li, J. Caro, Oriented zeolitic imidazolate framework- 8 membrane with sharp $\mathrm{H}_{2} / \mathrm{C}_{3} \mathrm{H}_{8}$ molecular sieve separation, Chem. Mater. 23 (2011) 2262-2269. doi:10.1021/cm200555s.

[8] Y. Zhang, Z. Wu, Z. Hong, X. Gu, N. Xu, Hydrogen-selective zeolite membrane reactor for low temperature water gas shift reaction, Chem. Eng. J. 197 (2012) 314-321. doi:10.1016/j.cej.2012.05.064.

[9] M.E. Rezac, W.J. Koros, S.J. Miller, Membrane-assisted dehydrogenation of n-butane; 
Influence of membrane properties on system performance, J. Memb. Sci. 93 (1994) $193-$ 201. doi:10.1016/0376-7388(94)80007-3.

[10] V.M.A. Melgar, J. Kim, M.R. Othman, Zeolitic Imidazolate Framework Membranes for Gas Separation: A Review of Synthesis Methods and Gas Separation Performance, J. Ind. Eng. Chem. 28 (2015) 1-15. doi:10.1016/j.jiec.2015.03.006.

[11] H. Yin, H. Kim, J. Choi, A. C. K. Yip, Thermal stability of ZIF-8 under oxidative and inert environments: A practical perspective on using ZIF-8 as a catalyst support, Chem. Eng. J. 15 (2014) 293-300. doi:10.1016/j.cej.2014.08.075.

[12] B.R. Pimentel, A. Parulkar, E. Zhou, N.A. Brunelli, R.P. Lively, Zeolitic imidazolate frameworks: Next-generation materials for energy-efficient gas separations, ChemSusChem. 7 (2014) 3202-3240. doi:10.1002/cssc.201402647.

[13] M.E. Brown, Steps in a minefield. Some kinetic aspects of thermal analysis, J. Therm. Anal. 49 (1997) 17-32.

[14] Y. Pan, Y. Liu, G. Zeng, L. Zhao, Z. Lai, Rapid synthesis of zeolitic imidazolate framework-8 (ZIF-8) nanocrystals in an aqueous system, Chem. Commun. 47 (2011) 2071-2073. doi:10.1039/c0cc05002d.

[15] J.B. James, Y.S. Lin, Kinetics of ZIF-8 thermal decomposition in inert, oxidizing and reducing environments, J. Phys. Chem. C. (2016) doi:10.1021/acs.jpcc.6b01208.

[16] Y. Li, F. Liang, H. Bux, W. Yang, J. Caro, Zeolitic imidazolate framework ZIF-7 based molecular sieve membrane for hydrogen separation, J. Memb. Sci. 354 (2010) 48-54. doi:10.1016/j.memsci.2010.02.074.

[17] T. Yang, T.S. Chung, High performance ZIF-8/PBI nano-composite membranes for high temperature hydrogen separation consisting of carbon monoxide and water vapor, Int. J. Hydrogen Energy. 38 (2013) 229-239. doi:10.1016/j.ijhydene.2012.10.045.

[18] A. Huang, W. Dou, J. Caro, Steam-stable zeolitic imidazolate framework ZIF-90 membrane with hydrogen selectivity through covalent functionalization, J. Am. Chem. Soc. 132 (2010) 15562-15564. doi:10.1021/ja108774v.

[19] Q. Liu, N. Wang, J. Caro, A. Huang, Bio-inspired polydopamine: A versatile and powerful platform for covalent synthesis of molecular sieve membranes, J. Am. Chem. Soc. 135 
(2013) 17679-17682. doi:10.1021/ja4080562.

[20] A. Huang, Q. Liu, N. Wang, J. Caro, Highly hydrogen permselective ZIF-8 membranes supported on polydopamine functionalized macroporous stainless-steel-nets, J. Mater. Chem. A. 2 (2014) 8246-8251. doi:10.1039/C4TA00299G.

[21] X. Zhang, Y. Liu, S. Li, L. Kong, H. Liu, Y. Li, W. Han, K. L. Yeung, W. Zhu, W. Yang, J. Qiu, New membrane architecture with high performance : ZIF-8 membrane supported on vertically-aligned $\mathrm{ZnO}$ nanorods for gas permeation and separation, Chem. Mater. 26 (2014) 1975-1981. doi:10.1021/cm500269e.

[22] M. Drobek, M. Bechelany, C. Vallicari, A. Abou Chaaya, C. Charmette, C. SalvadorLevehang, P. Miele, A. Julbe, An innovative approach for the preparation of confined ZIF-8 membranes by conversion of ZnO ALD layers, J. Memb. Sci. 475 (2015) 39-46. doi:10.1016/j.memsci.2014.10.011.

[23] D. Liu, X. Ma, H. Xi, Y. S. Lin, Gas transport properties and propylene/propane separation characteristics of ZIF-8 membranes, J. Memb. Sci. 451 (2014) 85-93. doi:10.1016/j.memsci.2013.09.029.

[24] J. Cravillon, R. Nayuk, S. Springer, A. Feldhoff, K. Huber, M. Wiebcke, Controlling zeolitic imidazolate framework nano- and microcrystal formation: Insight into crystal growth by time-resolved in situ static light scattering, Chem. Mater. 23 (2011) 2130-2141. doi:10.1021/cm103571y.

[25] Y. Pan, T. Li, G. Lestari, Z. Lai, Effective separation of propylene/propane binary mixtures by ZIF-8 membranes, J. Memb. Sci. 390-391 (2012) 93-98. doi:10.1016/j.memsci.2011.11.024.

[26] L. Zhang, G. Wu, J. Jiang, Adsorption and diffusion of $\mathrm{CO}_{2}$ and $\mathrm{CH}_{4}$ in zeolitic imidazolate framework-8: Effect of structural flexibility, J. Phys. Chem. C. 118 (2014) 140411102121001. doi:10.1021/jp500796e.

[27] D. Liu, Y. Wu, Q. Xia, Z. Li, H. Xi, Experimental and molecular simulation studies of $\mathrm{CO}_{2}$ adsorption on zeolitic imidazolate frameworks: ZIF-8 and amine-modified ZIF-8, Adsorption. 19 (2013) 25-37. doi:10.1007/s10450-012-9407-1.

[28] H. Amrouche, S. Aguado, J. Pèrez-Pellitero, C. Chizallet, F. Siperstein, D. Farrusseng, N. Bats, C. Nieto-Draghi, Experimental and computational study of functionality impact on sodalite-zeolitic imidazolate frameworks for $\mathrm{CO}_{2}$ separation, J. Phys. Chem. C. 115 
(2011) 16425-16432. DOI: 10.1021/jp202804g.

[29] J. Pérez-Pellitero, H. Amrouche, F.R. Siperstein, G. Pirngruber, C. Nieto-Draghi, G. Chaplais, A. Simon-Masseron, D. Bazer-Bachi, D. Peralta, N. Bats, Adsorption of $\mathrm{CO}_{2}$, $\mathrm{CH}_{4}$, and $\mathrm{N}_{2}$ on zeolitic imidazolate frameworks: Experiments and simulations, Chem. Eur. J. 16 (2010) 1560-1571. doi:10.1002/chem.200902144.

[30] B. Assfour, S. Leoni, G. Seifert, Hydrogen adsorption sites in zeolite imidazolate frameworks ZIF-8 and ZIF-11, J. Phys. Chem. C. 114 (2010) 13381-13384. doi:10.1021/jp101958p.

[31] H. Wu, W. Zhou, T. Yildirim, Hydrogen storage in a prototypical zeolitic imidazolate framework-8, J. Am. Chem. Soc. 129 (2007) 5314-5315. doi:10.1021/ja0691932.

[32] C. Zhang, R.P. Lively, K. Zhang, J.R. Johnson, O. Karvan, W.J. Koros, Unexpected molecular sieving properties of zeolitic imidazolate framework-8, J. Phys. Chem. Lett. 3 (2012) 2130-2134. doi:10.1021/jz300855a.

[33] W.J.W. Bakker, F. Kapteijn, J. Poppe, J. A. Moulijn, Permeation characteristics of a metal-supported silicalite-1 zeolite membrane, J. Memb. Sci. 117 (1996) 57-78. doi:10.1016/0376-7388(96)00035-X.

[34] M. Kanezashi, Y.S. Lin, Gas Permeation and Diffusion Characteristics of MFI-Type Zeolite Membranes at High Temperatures, J. Phys. Chem. C. 113 (2009) 3767-3774. doi:10.1021/jp804586q.

[35] X. Ma, B.K. Lin, X. Wei, J. Kniep, Y.S. Lin, Gamma-alumina supported carbon molecular sieve membrane for propylene/propane separation, Ind. Eng. Chem. Res. 52 (2013) 4297 4305. doi:10.1021/ie303188c.

[36] H.T. Kwon, H. Jeong, A.S. Lee, H.S. An, J.S. Lee, Heteroepitaxially grown zeolitic imidazolate framework membranes with unprecedented propylene/propane separation performances, J. Am. Chem. Soc. 137 (2015) 12304-12311. doi:10.1021/jacs.5b06730.

[37] G. Xu, J. Yao, K. Wang, L. He, P.A. Webley, C. Chen, H. Wang, Preparation of ZIF-8 membranes supported on ceramic hollow fibers from a concentrated synthesis gel, J. Memb. Sci. 385-386 (2011) 187-193. doi:10.1016/j.memsci.2011.09.040.

[38] M. Rungta, L. Xu, W.J. Koros, Carbon molecular sieve dense film membranes derived from Matrimid® for ethylene/ethane separation, Carbon 50 (2012) 1488-1502. doi:10.1016/j.carbon.2011.11.019. 
[39] M.J.C. Ordoñez, K.J. Balkus, J.P. Ferraris, I.H. Musselman, Molecular sieving realized with ZIF-8/Matrimid® mixed-matrix membranes, J. Memb. Sci. 361 (2010) 28-37. doi:10.1016/j.memsci.2010.06.017.

[40] Y. Hu, H. Kazemian, S. Rohani, Y. Huang, Y. Song, In situ high pressure study of ZIF-8 by FTIR spectroscopy, Chem. Commun. $47 \quad$ (2011) 12694-12696. doi:10.1039/c1cc15525c.

[41] S. Gadipelli, W. Travis, W. Zhou, Z. Guo, A thermally derived and optimized structure from ZIF-8 with giant enhancement in CO2 uptake, Energy Environ. Sci. 7 (2014) 22322238. doi:10.1039/c4ee01009d.

[42] J. Kim, D. Lee, Marked inducing effects of metal oxide supports on the hydrothermal stability of zeolitic imidazolate framework (ZIF) membranes, J. Mater. Chem. A. 4 (2016) 5205-5215. doi:10.1039/C5TA10190E. 


\section{List of Figure Captions}

\begin{tabular}{|c|c|}
\hline Figure 1. & Binary gas permeance apparatus and configuration \\
\hline Figure 2. & $\begin{array}{l}\text { SEM micrograph of as-synthesized ZIF-8 membrane: cross section (A) and top view at 5000x } \\
\text { magnification (B) }\end{array}$ \\
\hline Figure 3. & XRD pattern of as-synthesized ZIF-8 membrane on alumina support \\
\hline Figure 4. & $\begin{array}{l}\mathrm{ZIF}-8 \text { membrane } \mathrm{H}_{2} \text { and } \mathrm{CO}_{2} \text { single gas permeance as a function of temperature from } 25 \text { - } \\
250^{\circ} \mathrm{C}\end{array}$ \\
\hline Figure 5. & $\begin{array}{l}\mathrm{ZIF}-8 \text { membrane binary } \mathrm{H}_{2} / \mathrm{CO}_{2} \text { permeance and separation factor as a function of temperature } \\
\text { from } 25-300^{\circ} \mathrm{C}\end{array}$ \\
\hline Figure 6. & $\begin{array}{l}\text { TGA weight decomposition profile of ZIF- } 8 \text { crystals using a temperature profile and } \mathrm{H}_{2} / \mathrm{CO}_{2} \\
\text { atmosphere identical to temperature dependent permeation experiment }\end{array}$ \\
\hline Figure 7. & $\begin{array}{l}\mathrm{ZIF}-8 \text { membrane XRD spectra before and after binary } \mathrm{H}_{2} / \mathrm{CO}_{2} \text { temperature dependent }(25- \\
\left.300^{\circ} \mathrm{C}\right) \text { permeance study }\end{array}$ \\
\hline Figure 8. & $\begin{array}{l}\text { ZIF- } 8 \text { membrane SEM micrographs after temperature dependent }\left(25-300^{\circ} \mathrm{C}\right) \text { binary } \mathrm{H}_{2} / \mathrm{CO}_{2} \\
\text { experiment: cross-section } \\
\text { (A), top views (B-D) }\end{array}$ \\
\hline Figure 9. & $\begin{array}{l}\text { ZIF-8 powder XRD patterns before and after } \mathrm{H}_{2} / \mathrm{CO}_{2} \text { atmosphere temperature dependent (25- } \\
\left.300^{\circ} \mathrm{C}\right) \text { TGA experiment }\end{array}$ \\
\hline $\begin{array}{l}\text { Figure } \\
10 .\end{array}$ & $\begin{array}{l}\text { Transient profiles of ZIF- } 8 \text { membrane } \mathrm{H}_{2} / \mathrm{CO}_{2} \text { mixture permeance and separation factor with } \\
\text { respect to time at isothermal temperatures of (A) } 50^{\circ} \mathrm{C} \text {, (B) } 100^{\circ} \mathrm{C} \text { and }(\mathrm{C}) 150^{\circ} \mathrm{C} \text { ( } 24 \text { hours) }\end{array}$ \\
\hline $\begin{array}{l}\text { Figure } \\
11 .\end{array}$ & $\begin{array}{l}\text { ZIF- } 8 \text { membrane XRD patterns before and after } 24 \text { hour binary } \mathrm{H}_{2} / \mathrm{CO}_{2} \text { separation isothermal } \\
\text { study at } \\
\text { (A) } 50^{\circ} \mathrm{C} \text {, (B) } 100^{\circ} \mathrm{C} \text { and (D) } 150^{\circ} \mathrm{C}\end{array}$ \\
\hline $\begin{array}{l}\text { Figure } \\
12 .\end{array}$ & $\begin{array}{l}\text { SEM micrographs of ZIF- } 8 \text { membranes post binary } \mathrm{H}_{2} / \mathrm{CO}_{2} 24 \text { hour transient separation } \\
\text { studies at isothermal } \\
\text { temperatures of (A) } 50^{\circ} \mathrm{C}, \text { (B) } 100^{\circ} \mathrm{C} \text { and (C) } 150^{\circ} \mathrm{C}\end{array}$ \\
\hline $\begin{array}{l}\text { Figure } \\
13 .\end{array}$ & $\begin{array}{l}\text { ZIF- } 8 \text { membrane } \mathrm{H}_{2} / \mathrm{CO}_{2} \text { mixture permeance and separation factor with respect to time during } \\
300^{\circ} \mathrm{C} \\
\text { isothermal transient experiment ( } 24 \text { hours) }\end{array}$ \\
\hline
\end{tabular}


\begin{tabular}{l|l} 
Figure & ZIF-8 membrane XRD patterns before and after 24 hour binary $\mathrm{H}_{2} / \mathrm{CO}_{2}$ separation isothermal
\end{tabular} 14. study at $300^{\circ} \mathrm{C}$

Figure

15.

ZIF-8 membrane SEM micrographs post $300^{\circ} \mathrm{C}$ isothermal transient binary $\mathrm{H}_{2} / \mathrm{CO}_{2}$ experiment: 5,000X magnification (A), 15,000X magnification (B) and 20,000X magnification (C)

Figure

16.
FTIR spectra of ZIF-8 membranes held in $\mathrm{H}_{2} / \mathrm{CO}_{2}$ atmosphere after $25-300^{\circ} \mathrm{C}$ temperature dependent experiment and 24 hour transient isothermal experiments at 50,100,150, and $300^{\circ} \mathrm{C}$ respectively all relative to as-synthesized (fresh) ZIF-8 membrane spectrum 